\title{
Growth, Unemployment and Wage Inertia
}

\author{
Xavier Raurich* \\ Universitat de Barcelona and CREB \\ Valeri Sorolla ${ }^{\dagger}$ \\ Universitat Autònoma de Barcelona
}

April 2013

\begin{abstract}
We introduce wage setting via efficiency wages in the neoclassical one-sector growth model to study the growth effects of wage inertia. We compare the dynamic equilibrium of an economy with wage inertia with the equilibrium of an economy without it. We show that wage inertia affects the long run employment rate and that the transitional dynamics of the main economic variables will be different because wages are a state variable when wage inertia is introduced. In particular, we show that the model with wage inertia can explain some growth patterns that cannot be explained when wages are flexible. We also study the growth effects of permanent technological and fiscal policy shocks in these two economies. During the transition, the growth effects of technological shocks obtained when wages exhibit inertia may be the opposite of those obtained when wages are flexible. These technological shocks may have long run effects if there is wage inertia.
\end{abstract}

JEL classification codes: $\mathrm{O} 41$.

Keywords: wage inertia, growth, efficiency wages, transitional dynamics, unemployment.

*Departament de Teoria Econòmica, Universitat de Barcelona, Avda. Diagonal 690, 08034 Barcelona, Spain; email: xavier.raurich@ub.edu; tel.: +34-93.402.19.34.

†Departament d'Economia i d'Història Econòmica, Universitat Autònoma de Barcelona, Edifici B, 08193 Bellaterra, Spain. tel.: +34-93.581.27.28. e-mail: valeri.sorolla@uab.cat.

${ }^{\ddagger}$ Raurich and Sorolla gratefully acknowledge financial support from the Ministry of Science and Innovation through grants ECO2009-06953 and ECO2009- 09847; and from the Generalitat de Catalunya through grants 2009SGR-1051, 2009SGR-578 and the Barcelona GSE Research Network. The paper has also benefited from comments by David de la Croix, Victor Montuenga, Fernando Sanchez-Losada and seminar participants at the Academia Sinica, University of Milan and University of Vigo. 


\section{Introduction}

Wage inertia implies that current wages depend on past wages. ${ }^{1}$ This relationship is a well-known empirical fact in labor economics (see Bell, 1996; Blanchard and Katz, 1997 and the survey by Montuenga-Gómez and Ramos-Parreño, 2005). Moreover, wage inertia has been justified in different wage settings. In models of wage bargaining between unions and firms, the wage is set as a markup over a reference wage that is interpreted as a fall back position. This reference wage is typically related to the unemployment benefit, which, in most OECD countries depends on past wages. This introduces the relationship between current and past wages (Burkhard and Morgenstern, 2000 and Beissinger and Egger, 2004). Wage inertia has also been justified in efficiency wage models, where the wage is set by the firm in order to induce workers to exert the profit maximizing amount of effort (de la Croix and Collard, 2000; Danthine and Donaldson, 1990, and Danthine and Kurmann, 2004). In this wage setting, the wage also depends on a reference wage if fairness is introduced in workers' disutility of effort. This reference wage is frequently interpreted as a social norm that depends on past wages. In this way, wage inertia is introduced in the efficiency wage model. ${ }^{2}$ This second approach has some empirical support from survey evidence (Bewley, 2002).

Wage inertia introduces a process of wage adjustment that drives the transitional dynamics of wages and modifies the time path of the other variables in the economy, including the GDP growth rate. These differences in the transitional dynamics have been explored in New Keynesian models, where there is also price inertia, to explain facts of the business cycle and the effects of monetary shocks (Danthine and Kurmann, 2004; and Blanchard and Galí, 2007). However, wage inertia has not been introduced in growth models to explain facts of the growth process. ${ }^{3}$ Therefore, the purpose of this paper is to study how wage inertia modifies the time path of the GDP growth rate, and to show that a simple version of the neoclassical growth model with wage inertia can explain two facts of the growth process that could not be explained if wages were flexible. First, we explain the high growth rates that some emerging economies have exhibited over long periods

\footnotetext{
${ }^{1}$ The literature also refers to wage inertia as persistence or sluggishness.

${ }^{2}$ In efficiency wage models, wages are typically flexible. By flexible wages we mean that there is no wage inertia and, thus, current wages do not depend on past wages. However, it does not mean that this flexible wage clears the labor market and, hence, there is full employment. The assumption of a reference wage that depends on past wages is then crucial to introduce wage inertia.

${ }^{3}$ Growth models with wage bargaining between firms and unions and non frictional unemployment have been studied by Benassy (1997), Daveri and Tabellini (2000), Braüninger (2000), Daveri and Mafezzoli (2000), Doménech and García (2008) and growth models with efficiency wages have been studied by Van Shaik and de Groot (1998), Alexopoulos (2003), Mekl (2004), Nakajima (2006), Brecher, Chen and Choudhri (2002) and Pierpaolo (2010). In all these papers, wages do not exhibit inertia. Two exceptions that introduce wage inertia in a growth model are the papers by Raurich, Sala and Sorolla (2006) and Greiner and Flaschel (2010). However, these two papers only study the long run growth effects of the interaction between wage inertia and some particular fiscal policies.
} 
of time. ${ }^{4}$ According to King and Rebelo (1993) the neoclassical growth model requires implausibly high interest rates to explain these large growth rates. We show that taking into account labor market dynamics driven by wage inertia may explain high growth rates with plausible values of the interest rate.

Second, Easterly (1991), Christiano (1989) and, more recently, Steger (2001), Papageorgiou and Perez-Sebastian (2005) and Jeong and Yong Kim (2006, 2008) show that some fast growing economies exhibit a hump-shaped transition of the GDP growth rate. The neoclassical growth model implies a monotonic transition and thus it cannot explain this fact. We show that a version of this model that introduces wage inertia can explain these hump-shaped transitions.

We analyze a version of the neoclassical one-sector exogenous growth model with efficiency wages. In the model, wages are set by firms in order to make workers exert an amount of effort that maximizes profits. These non-walrasian wages cause nonfrictional unemployment. We assume that the workers' disutility of effort depends on the comparison between current wages and a reference wage. Therefore, the amount of effort exerted by workers will depend on this comparison and, as a consequence, wages will be set by the firms in relation to this reference wage. Until Section 5 , the reference wage is external to the individuals and it is interpreted as a social norm that depends on past average labor income. It follows that current wages depend on past wages, implying that wage inertia is introduced and that wages are a state variable. Therefore, in this version of the neoclassical growth model, two forces drive the transition: first, as in the neoclassical growth model with full employment, the diminishing returns to capital; and second, the process of wage adjustment.

We distinguish between two effects of wage inertia. On the one hand, the time path of the employment rate depends on both capital accumulation and the process of wage adjustment. Capital accumulation increases labor demand and, thus, increases employment. Wage growth reduces employment. Thus, a fast (slow) accumulation of capital in comparison to the speed of wage adjustment will imply an increase (decrease) in the employment rate. Therefore, the interaction between capital accumulation and wage adjustment can explain periods of fast employment creation and also non-monotonic transitions of the employment rate that are not present when wages are flexible.

On the other hand, the returns on capital and wages are related because we assume perfect competition and constant returns to scale. Then, wage inertia modifies the time path of capital accumulation because it changes the returns on capital. In particular, if wages are initially high then the interest rate will initially be low, implying low capital accumulation. The opposite holds when wages are initially low. Moreover, a process of

\footnotetext{
${ }^{4}$ Taiwan, South Korea and Singapore had annual growth rates of more than $6 \%$ during the period 1960-2000.
} 
fast wage adjustment also causes fast changes in capital accumulation.

During the transition, the GDP growth rate depends on the exogenous growth rate of technology, capital accumulation and the growth rates of both employment and effort. The particular assumptions of the model regarding the disutility of effort and the reference wage imply a constant optimal amount of effort during the transition. Therefore, wage inertia modifies the GDP growth rate by changing both capital accumulation and employment growth. These changes modify the time path of the GDP growth rate, which may exhibit non-monotonic transitions. In Section 4, we compare this transitional dynamics with the one obtained in a version of the neoclassical growth model with flexible wages. In this case, increases in productivity, due to either capital accumulation or exogenous productivity shocks, translate completely into wage increases and do not affect the employment rate, which is constant. Then, as in the neoclassical model with full employment, the GDP growth rate only depends on capital accumulation, and therefore transitional dynamics will exhibit a monotonic behavior.

In Section 4, we use numerical simulations to study the effects of wage inertia during the transition. First, we show that in economies with an initial high wage, the employment rate is initially low and increasing. As a consequence, in these economies, the growth rate of GDP will initially be large and then decrease during the transition. In contrast, initial low wages imply that the employment rate will initially be high and then decrease during the transition. This implies that the growth rate of GDP will initially be low and will increase during the transition. We conclude that economies with the same initial stock of capital may exhibit different time paths of the growth rate of GDP if their initial wages are different. This suggests that the introduction of initial wages in the empirical analysis of convergence may improve the estimation's fit.

We also show that wage inertia can generate a process of fast employment creation that may cause both a hump-shaped transition of the GDP growth rate and high GDP growth rates. Before this process starts, GDP growth will be low. Then, during the process of employment growth, the GDP growth rate will be high due to the increasing employment rate. Finally, when the creation of employment ends, the GDP growth rate decreases until it converges to its long run value. Moreover, during the period of employment creation, the GDP growth rates are very high even when the interest rates take plausible values. As mentioned, there is evidence that some emerging economies have exhibited these transitions in recent decades. We conclude that the introduction of wage inertia may contribute to explain some facts of the growth process.

In the second part of Section 4, we compare the growth effects of technological shocks in the model with flexible wages and in the model with wage inertia. We consider two different technological shocks: a permanent increase in the level of total factor productivity (TFP) and a permanent increase in the growth rate of TFP. While the second shock 
causes permanent effects on the employment rate and the growth rate, the first shock has only transitional effects on the GDP growth rate. However, these transitional effects will depend on the intensity of wage inertia. When wages are flexible, employment does not change and transitional dynamics are driven only by diminishing returns to capital. In this case, the shock initially increases the marginal product of capital, and therefore the GDP growth rate increases. When there is wage inertia, this shock implies an initial increase in the employment rate and a decrease in this variable during the transition. This causes a negative effect on GDP growth that is not present when wages are flexible. This negative growth effect dominates the positive growth effect associated to capital accumulation during the first periods and, therefore, this shock initially reduces the GDP growth rate. Thus, the effects on the GDP growth rate of a permanent increase in the level of TFP depend on the intensity of wage inertia. ${ }^{5}$

The second shock, the permanent increase in the growth rate of TFP, implies a faster growth of the marginal product of labor. Flexible wages adjust immediately to this faster growth of the marginal product, implying that the employment rate does not change. In contrast, when there is wage inertia, wages do not adjust to this faster growth of the marginal product. As a consequence, when there is wage inertia, this technological shock causes an increase in the employment rate both during the transition and in the long run. Therefore, wage inertia introduces a positive relationship between the exogenous long run growth rate and the long run employment rate that is supported by empirical evidence. ${ }^{6}$ Note that, by interpreting the productivity growth slowdown in the 1970 s as a reduction in the TFP growth rate, this positive relationship explains the persistently high unemployment rates in Europe.

Finally, we study the growth effects of the introduction of an unemployment benefit. This unemployment benefit raises the reference wage and, therefore, wages increase. If wages are flexible, they immediately adjust, implying an immediate jump downwards in both employment and GDP. When there is wage inertia, wages do not immediately adjust to this fiscal policy and, therefore, the employment rate and the level of GDP will suffer a slow decline. Thus, the macroeconomic effects of this fiscal policy suffer a delay when wages exhibit inertia.

Section 5 studies the robustness of the conclusions obtained in Section 4 when the reference wage is internal instead of external. This internal reference wage is interpreted as a personal norm that depends on the workers' past labor income. In this case, firms must take into account that an increase in current wages raises the future reference wage

\footnotetext{
${ }^{5}$ Basu et. al. (2006) provides evidence that technological improvements can be contractionary.

${ }^{6}$ As mentioned in Benigno, Ricci and Surico (2011), many authors show time series and cross-country evidence in favor of a negative relationship between unemployment and productivity growth at low frequencies. In fact, these authors find a similar result in a model with downward wage rigidity and without capital.
} 
and thus reduces effort in the future. Therefore, the profit maximization problem of the firms is dynamic and implies a non constant optimal time path of effort. This non-constant time path directly affects the GDP growth rate during the transition. However, using the numerical examples of Section 4, we show that the main conclusions regarding the growth effects of wage inertia hold when the reference wage is internal.

The paper is organized as follows. Section 2 presents the model. Section 3 defines the equilibrium. Section 4 develops the numerical analysis that is used to study the transitional dynamics when there is wage inertia. Section 5 studies the transition in the internal reference wage model. Section 6 contains some concluding remarks.

\section{The economy}

In this section we first describe the problem of the consumers; we then introduce the technology and the optimal decisions of the firms, and, finally, we specify a wage setting rule with wage inertia.

\subsection{Consumers}

Consider an economy populated by $N_{t}$ ex ante identical infinitely lived consumers. Each consumer chooses consumption, $C_{t}$, and effort, $e_{t}^{f}$, in order to maximize the discounted sum of the utility

$$
\int_{t=0}^{\infty} e^{-(\rho-n) t}\left[u\left(C_{t}\right)-d_{t} v_{t}\left(e_{t}^{f}\right)\right] d t,
$$

where $\rho>0$ is the subjective discount rate, $n \geq 0$ is the constant population growth rate, $d_{t}$ is a dummy variable that equals 1 if the consumer is employed and equals 0 if he is unemployed. The utility function is separable in consumption and effort. We assume that $u\left(C_{t}\right)$ is a twice continuously differentiable utility function, increasing and concave, which satisfies the Inada conditions. Following Akerlof (1982), we introduce fairness in the disutility of effort. In particular, we assume the following functional form:

$$
v_{t}\left(e_{t}^{f}\right)=\left[e_{t}^{f}-\ln \left(\frac{(1-\tau) w_{t}}{\widetilde{\gamma} w_{t}^{s}}\right)\right]^{2},
$$

where $\tau$ is the labor income tax rate, $w_{t}$ is the wage, $w_{t}^{s}$ is an external reference wage and $\widetilde{\gamma}>0$ is a preference parameter. Note that the consumers' disutility of effort decreases if they feel that they are well paid, which happens when the wage net of taxes is larger than the reference wage. Obviously, the disutility increases when consumers do not consider that they are well paid.

There is no consensus in the literature on the determinants of the reference wage. 
Layard et al. (1991, chapter 2) identifies it with the average labor income. Blanchard and Katz (1999) and Blanchard and Wolfers (2000) assume that the reference wage also depends on past wages. Using survey data, Bewley (2002) provides evidence on the relation between the reference wage and past wages. We follow these authors and we interpret the reference wage as a social norm that depends on the average past labor income in the economy. As a consequence, it is external to the individual. This assumption is crucial as it implies that firms do not consider that their decisions today can modify the current or future value of the reference wage. In Section 5 we also study the equilibrium when the reference wage is internal because it is interpreted as a personal norm that depends on the worker's own past labor income.

In each period $t$ a fraction of the consumers will be unemployed. As a consequence, there is ex post heterogeneity. To avoid the complexity associated with ex post heterogeneity, we follow Collard and de la Croix (2000) and introduce unemployment insurance contracts which are not affected by transaction costs and are offered by risk neutral insurance companies. Thus, risk averse consumers choose complete insurance against the risk of being unemployed. This means that the income of employed and unemployed consumers will coincide, implying that consumers are ex post identical. ${ }^{7}$ If consumers are employed, they obtain

$$
I_{t}^{e}=(1-\tau) w_{t}-m_{t}
$$

where $m_{t}$ is the cost of unemployment insurance. If consumers are unemployed, they obtain

$$
I_{t}^{u}=b_{t}+\frac{m_{t}}{1-l_{t}}-m_{t}
$$

where $b_{t}$ is the unemployment benefit, $m_{t} /\left(1-l_{t}\right)$ is the unemployment insurance and $l_{t}$ is the employment rate, which is defined as the ratio between the number of employed workers and the total labor force. The labor income of both employed and unemployed workers coincides when the cost of the insurance is

$$
m_{t}=\left[(1-\tau) w_{t}-b_{t}\right]\left(1-l_{t}\right)
$$

\footnotetext{
${ }^{7}$ Collard and de la Croix (2000) show that this contract exists.
} 
In this case, $I_{t}^{e}=I_{t}^{u}=I_{t}$, where $I_{t}$ is the average labor income and it is defined as ${ }^{8}$

$$
I_{t}=(1-\tau) w_{t} l_{t}+b_{t}\left(1-l_{t}\right)
$$

Therefore, the budget constraint of the representative consumer is

$$
\dot{S}_{t}=r_{t} S_{t}+I_{t}+T_{t}-C_{t}
$$

where $S_{t}$ is the stock of assets, $I_{t}$ is the labor income and $T_{t}$ is a lump-sum subsidy.

The consumer decides optimally on effort, consumption and investment by maximizing the discounted sum of utilities subject to the budget constraint. The solution of the maximization problem of the consumers is characterized by the effort function

$$
e_{t}^{f}=\ln \left[(1-\tau) w_{t}\right]-\ln \left(\widetilde{\gamma} w_{t}^{s}\right),
$$

the Euler condition

$$
\frac{\dot{C}_{t}}{C_{t}}=\frac{r_{t}-\rho}{\sigma\left(C_{t}\right)},
$$

where $\sigma\left(C_{t}\right)=-u^{\prime \prime}\left(C_{t}\right) C_{t} / u^{\prime}\left(C_{t}\right)$, the budget constraint, and the following transversality condition:

$$
\lim _{t \longrightarrow \infty} e^{-\rho t} u^{\prime}\left(C_{t}\right) S_{t}=0
$$

\section{$2.2 \quad$ Firms}

There is a continuum of firms distributed in the interval $[0,1]$. These firms produce using the following neoclassical production function:

$$
Y_{t}=F\left(K_{t}, e_{t}^{f} A_{t} L_{t}\right)
$$

where $Y_{t}$ is gross domestic product (GDP), $K_{t}$ is capital, $e_{t}^{f}$ is effort, $A_{t}$ is technology and $e_{t}^{f} A_{t} L_{t}$ are efficiency units of employed labor. We assume that technology, $A_{t}$, exogenously increases at a constant growth rate $x \geq 0$, and that the production function satisfies the following properties: constant returns to scale, twice continuously differentiable, $F_{1}>0$, $F_{2}>0, F_{11}<0, F_{22}<0$ and the Inada conditions. ${ }^{9}$ Note that effort increases the productivity of labor. This is taken into account by firms that set wage contracts as a

\footnotetext{
${ }^{8}$ Expost heterogeneity associated to unemployment can also be avoided by assuming that all members of the economy belong to the same big family. Daveri and Maffezzoli (2000), Doménech and García (2008), Eriksson (1997) follow this big family assumption. If instead of a big family we have heterogeneous agents, the solution would not change as long as we assume complete competitive insurance markets for unemployment or if we assume that a union pursues a redistributive goal, acting as a substitute for the insurance markets (Maffezzoli, 2001 and Benassy, 1997).
}

${ }^{9}$ We define $F_{1}=\partial F / \partial K$, and $F_{2}=\partial F / \partial\left(e_{t}^{f} A_{t} L_{t}\right)$. 
partial gift exchange: in exchange for higher salaries, workers will exert a higher amount of effort. Obviously, these non-walrasian wages will create unemployment in this model.

Firms take into account the effort function when they maximize profits, $F\left(K_{t}, e_{t}^{f} A_{t} L_{t}\right)-w_{t} L_{t}-\left(r_{t}+\delta\right) K_{t}$, where $r_{t}$ is the interest rate and $\delta \in(0,1)$ is the constant depreciation rate. The first order conditions with respect to capital, labor and wages imply

$$
\begin{gathered}
r_{t}=F_{1}-\delta, \\
w_{t}=e_{t}^{f} A_{t} F_{L},
\end{gathered}
$$

and

$$
\frac{\partial e_{t}^{f}}{\partial w_{t}} \frac{w_{t}}{e_{t}^{f}}=1 .
$$

The third equation is the Solow condition. From combining the effort function and the Solow condition, we obtain that $e_{t}^{f}=1$ is the amount of effort that maximizes profits. Therefore, this optimal amount of effort of employed workers is constant through the transition. As shown by de la Croix, de Walque and Wouters (2009) the optimal amount of effort is constant because the effort function assumed is log-linear. Using this constant effort level and the constant returns to scale assumption, (6) can be rewritten as

$$
\widehat{w}_{t}=f\left(\widehat{k}_{t}\right)-\widehat{k}_{t} f^{\prime}\left(\widehat{k}_{t}\right)
$$

where $\widehat{w}_{t}=w_{t} / A_{t}$ is the wage per efficiency units of labor, $\widehat{k}_{t}=K_{t} / A_{t} L_{t}$ is capital per efficiency units of employed labor, and the production function in intensive form satisfies the following properties: $f^{\prime}>0$ and $f^{\prime \prime}<0$. Using (8), we obtain

$$
\widehat{k}_{t}=\tilde{k}\left(\widehat{w}_{t}\right)
$$

where $\tilde{k}^{\prime}>0$ and from (9) we obtain the labor demand function

$$
L_{t}^{d}=\frac{K_{t}}{A_{t} \tilde{k}\left(\widehat{w}_{t}\right)} .
$$

Combining (5) and (9), we obtain the zero profit condition as a function relating the interest rate and wages

$$
r_{t}=f^{\prime}\left[\tilde{k}\left(\widehat{w}_{t}\right)\right]-\delta \equiv \widetilde{r}\left(\widehat{w}_{t}\right)
$$

where $\widetilde{r}^{\prime}<0$. Thus, if wages increase faster than efficiency units of labor, the interest rate decreases in order to have zero profits.

We assume that the labor supply is exogenous and equal to population, $N_{t}$. Population grows at a constant rate $n .{ }^{10}$ Using the labor supply, we define GDP per efficiency units

\footnotetext{
${ }^{10}$ Conclusions regarding the growth effects of wage inertia would not be modified if an endogenous
} 
of labor (population) $y_{t}=Y_{t} / A_{t} N_{t}$, capital per efficiency units of labor (population) $k_{t}=K_{t} / A_{t} N_{t}$ and the employment rate $l_{t}=L_{t} / N_{t} \in[0,1]$. Moreover, we use the constant returns to scale assumption to rewrite the production function as follows

$$
y_{t}=g\left(k_{t}, l_{t}\right)
$$

In models with wage setting, factor markets do not clear if the wage is different from the competitive walrasian wage. When the wage is lower than the walrasian wage, there is excess supply in the capital market and excess demand in the labor market; and if the wage is higher than the walrasian wage then there is excess demand in the capital market and excess supply in the labor market. In this paper, we will consider the latter case, which implies that the equilibrium stock of capital is determined by the supply and the equilibrium level of employment is determined by the labor demand, that is

$$
L_{t}=\frac{K_{t}}{A_{t} \tilde{k}\left(\widehat{w}_{t}\right)}
$$

Using (12), we obtain the employment rate function

$$
l_{t}=\widetilde{l}\left(\widehat{w}_{t}, k_{t}\right)=\frac{k_{t}}{\tilde{k}\left(\widehat{w}_{t}\right)}
$$

Note that the employment rate increases with the capital stock and decreases with the wages per efficiency unit. Finally, we use (13) to rewrite the ratio of GDP to capital as the following decreasing function of wages:

$$
\frac{y_{t}}{k_{t}}=g\left(1, \frac{1}{\tilde{k}\left(\widehat{w}_{t}\right)}\right)=h\left[\tilde{k}\left(\widehat{w}_{t}\right)\right], \quad h^{\prime}<0 .
$$

\subsection{Wage setting rule with inertia}

We first summarize the decisions of consumers and firms to obtain two well-known equations that make explicit the crucial role of wages in this model. To this end, we define $c_{t}=C_{t} / A_{t}$ as consumption per efficiency units of labor, we use the equilibrium condition of the capital market, $S_{t}=A_{t} k_{t}$, and we assume that the government budget constraint is balanced in each period and equal to

$$
\tau L_{t} w_{t}=N_{t} T_{t}+\left(N_{t}-L_{t}\right) b_{t}
$$

Note that tax revenues are returned to the consumers either as a lump-sum transfer or as unemployment benefit. Therefore, labor income taxes do not cause wealth effects in this labor supply had been assumed and leisure had been introduced additively in the utility function. 
economy.

Using equations (1), (3), (8), (11) and (14), the equilibrium condition in the capital market and the government budget constraint, we obtain

$$
\frac{\dot{c}_{t}}{c_{t}}=\frac{f^{\prime}\left[\tilde{k}\left(\widehat{w}_{t}\right)\right]-\delta-\rho-\sigma\left(c_{t} A_{t}\right) x}{\sigma\left(c_{t} A_{t}\right)}
$$

and

$$
\frac{\dot{k}_{t}}{k_{t}}=h\left[\tilde{k}\left(\widehat{w}_{t}\right)\right]-\frac{c_{t}}{k_{t}}-(n+x+\delta) .
$$

Equations (15) and (16) characterize the growth rates of consumption and capital per efficiency units of labor. These equations depend on the time path of the wage per efficiency unit of labor. On the one hand, a higher wage reduces the interest rate and causes a substitution effect that deters future capital accumulation. On the other hand, higher wages reduce the employment rate and, therefore, cause a negative wealth effect that reduces the rate of growth of capital. We conclude that the transitional dynamics of the one-sector growth model will depend on the particular assumptions regarding wage setting. We can distinguish three different wage settings.

First, if wages are flexible and are set in order to clear the markets, there is full employment, implying that $l_{t}=1$ and that $\tilde{k}\left(\widehat{w}_{t}\right)=k_{t}$. In this case, equations (15) and (16) characterize the dynamic equilibrium of the standard neoclassical growth model with full employment.

Second, if wages are flexible but are set above the competitive wage, markets do not clear and $l_{t}<1$. In this case, $\tilde{k}\left(\widehat{w}_{t}\right)=k_{t} / l_{t}$, where $l_{t}=\widetilde{l}\left(\widehat{w}_{t}, k_{t}\right)$ is defined in (13). Obviously, the system of differential equations (15) and (16) alone does not characterize the dynamic equilibrium. The equilibrium will also depend on the wage equation, which is obtained from the wage setting and determines the wage. The growth literature that studies the joint dynamics of growth and unemployment has considered this framework of non-walrasian wages without inertia. In this framework of flexible wages, the wage equation is static, implying that the equilibrium employment rate is either a function of capital or, under appropriate assumptions regarding the wage setting, constant during the transition. In the latter case, the transitional dynamics are identical to the ones obtained in the standard version of the neoclassical growth model with full employment.

Finally, if wages exhibit inertia, there is an additional dynamic equation that governs wage dynamics. In this paper we show that the transitional dynamics in this case are different from the ones obtained when wages do not exhibit inertia, and we outline that these differences can explain some facts of the growth process. We proceed to obtain the wage equation.

In the efficiency wage model considered in this paper, wages are set by the firm so 
that workers exert the optimal amount of effort, $e_{t}^{f}=1$. Using the effort function (2), it follows that wages set by the firm satisfy

$$
w_{t}=\frac{\gamma w_{t}^{s}}{1-\tau}
$$

where $\gamma=\widetilde{\gamma} e \geq 1$. Note that a higher value of $\gamma$ implies that firms must pay a higher wage in order to obtain the same amount of effort. Regarding the reference wage, in this paper we follow de la Croix and Collard (2000) and Raurich, et al. (2006) and assume that the reference wage is a social norm that is defined as the following weighted average of past average labor income:

$$
w_{t}^{s}=w_{0}^{s} e^{-\theta t}+\theta \int_{0}^{t} e^{-\theta(t-i)} I(i) d i
$$

where $w_{0}^{s}$ is the initial value of the reference wage, $\theta>0$ provides a measure of the wage adjustment rate and $I_{t}$ is the workers' average labor income

$$
I_{t}=(1-\tau) l_{t} w_{t}+\left(1-l_{t}\right) b_{t}
$$

with the unemployment benefits being $b_{t}=\lambda(1-\tau) w_{t}$ and $\lambda \in(0,1)$.

Note that a larger value of $\theta$ reduces the weights given to the past wages and thus implies a lower wage inertia. Therefore, $\theta$ provides a very convenient parametrization of the speed of wage adjustment. Moreover, if $\theta$ diverges to infinite, the reference wage coincides with the current average labor income and, in this limiting case, there is no wage inertia. Therefore, we must distinguish between the limiting case in which $\theta$ diverges to infinite and the case in which $\theta$ takes a finite value.

If $\theta$ diverges to infinite, (18) simplifies as follows: $w_{t}^{s}=I_{t}$. We solve the system of equations (17), (19) and $w_{t}^{s}=I_{t}$ to obtain that when wages do not exhibit inertia the employment rate is constant and equal to

$$
l_{t}=1+\frac{1-\gamma}{\gamma(1-\lambda)} \equiv \bar{l}
$$

An increase in the parameter $\gamma$ raises wages and thus reduces the employment rate. We will assume that $\gamma \in[1,1 / \lambda)$ in order that $\bar{l} \in(0,1]$. Note that there is full employment when $\gamma=1$, whereas there is unemployment when $\gamma>1$. Note also that the employment rate does not depend on the growth rate of the economy: in other words, it does not depend on capital accumulation or on technological progress. This result is a consequence of the fact that the increase in wages crowds out completely the positive effect on employment of capital accumulation or technological progress when wages are flexible. In the following section, we show that this complete crowding out does not arise when wages exhibit 
inertia.

If $\theta$ takes a finite value, wages exhibit inertia, implying that there is a process of wage adjustment. To characterize this process, we first obtain the law of motion of the reference wage by differentiating (18) with respect to time

$$
\dot{w}_{t}^{s}=\theta\left[I_{t}-w_{t}^{s}\right]
$$

Combining (17), (19) and (21), we obtain

$$
\frac{\dot{w}_{t}^{s}}{w_{t}^{s}}=\theta\left[\gamma(1-\lambda) l_{t}+\gamma \lambda-1\right]
$$

We log-differentiate (17) and $\widehat{w}_{t}=w_{t} / A_{t}$ and substitute the expression of the growth rate of the reference wage to obtain the growth rate of wages per efficiency unit of labor

$$
\frac{\widehat{\widehat{w}}_{t}}{\widehat{w}_{t}}=\theta\left[\gamma(1-\lambda) l_{t}+\gamma \lambda-1\right]-x
$$

Equation (22) is the dynamic wage equation of this model and it drives convergence in the labor market. To see this, assume that the employment rate is initially high. As a consequence, the average labor income is initially high, implying that the reference wage and wages will be higher in the future. As follows from (22), the growth of wages will initially be high in this case. The fast growth of wages causes a reduction in the employment rate. This reduction deters wage growth and makes wages per efficiency unit and employment converge to their long run value.

\section{Equilibrium}

We must distinguish between the equilibrium when $\theta$ diverges to infinite and wages are flexible and the equilibrium when wages exhibit inertia because $\theta$ takes a finite value.

Definition 1 Given the initial condition $k_{0}$, an equilibrium with flexible wages is a path $\left\{c_{t}, k_{t}, \widehat{w}_{t}, l_{t}\right\}$ that solves the system of differential equations (15) and (16), and satisfies (20), (13) and the transversality condition (4).

Definition 2 Given the initial conditions $k_{0}$ and $w_{0}$, an equilibrium with wage inertia is a path $\left\{c_{t}, k_{t}, \widehat{w}_{t}, l_{t}\right\}$ that solves the system of differential equations (15), (16), and (22), and satisfies (13) and the transversality condition (4).

Note that the main difference between these two equilibrium definitions is the number of state variables. The equilibrium with flexible wages is characterized by one control 
variable, $c_{t}$, and one state variable, $k_{t}$. The transition of this equilibrium is qualitatively equivalent to the transition in the neoclassical growth model with full employment because the employment rate remains constant. In fact, the model is the neoclassical growth model with full employment (the Ramsey-Cass-Koopmans model) when $\gamma=1$. Therefore, as in the growth model with full employment, if the initial level of capital is smaller (larger) than its long run level then the rate of growth of GDP is initially larger (smaller) than the long run growth rate, $x$, and decreases (increases) monotonically until convergence. We show that this transition is very different when wage inertia is introduced.

In order to simplify the analysis and obtain results, we assume the following isoelastic utility function:

$$
u\left(C_{t}\right)=\frac{C_{t}^{1-\sigma}-1}{1-\sigma}
$$

and the following Cobb-Douglas production function: ${ }^{11}$

$$
Y_{t}=K_{t}^{\alpha}\left(e_{t}^{f} A_{t} L_{t}\right)^{1-\alpha}, \alpha \in(0,1) .
$$

Proposition 3 There is a unique steady state equilibrium. The steady state values of the employment rate and of wages, capital, consumption and GDP per efficiency unit satisfy

$$
\begin{gathered}
l^{*}=1+\frac{1-\gamma}{(1-\lambda) \gamma}+\frac{x}{(1-\lambda) \gamma \theta}, \\
\widehat{w}^{*}=(1-\alpha)\left(\frac{\delta+\rho+\sigma x}{\alpha}\right)^{\frac{\alpha}{\alpha-1}}, \\
k^{*}=\left(\frac{\delta+\rho+\sigma x}{\alpha}\right)^{\frac{1}{\alpha-1}} l^{*}, \\
\frac{c^{*}}{k^{*}}=\frac{\delta+\rho+\sigma x}{\alpha}-(n+x+\delta), \\
\frac{y^{*}}{k^{*}}=\frac{\delta+\rho+\sigma x}{\alpha} .
\end{gathered}
$$

Note that the long run values of the ratios $y / k$ and $c / k$ and the wage $\widehat{w}^{*}$ do not depend on the parameters characterizing the labor market. Thus, the equilibrium of the one-sector growth model converges to the same values of these variables regardless of the wage setting assumed. However, the long run values of the employment rate and the levels of capital, GDP and consumption per efficiency units of population depend on both $\gamma$ and $\theta$. On the one hand, a larger value of $\gamma$ causes a reduction in the employment rate. This reduction implies a decrease in the levels of capital, consumption, and GDP. On the other hand, the employment rate increases with $x$ only if $\theta$ takes a finite value. The parameter $x$ measures the long run growth rate of per capita GDP. Therefore, wage inertia introduces a positive

\footnotetext{
${ }^{11}$ In Appendix A we obtain the expressions of the differential equations characterizing the equilibrium when the utility function is (23) and the production function is (24).
} 
relationship between the long run values of the growth rate and of the employment rate that is not present when wages are flexible. The intuition is as follows. Sustained growth implies that the labor demand increases at the growth rate $x$. Wage inertia prevents wages from increasing with the labor demand, which explains the positive effect on the employment rate. The same intuition explains that the employment rate decreases with the speed of wage adjustment, $\theta$, when there is sustained growth. This result contributes to the literature that analyzes the long run relationship between growth and employment in different wage settings and in different growth models. This literature has proposed different mechanisms explaining a positive (or negative) relationship between these two variables. In this paper, we show that wage inertia is another mechanism relating growth with employment in the long run.

Proposition 4 The steady state equilibrium of the economy with wage inertia is locally saddle path stable.

This result shows that there is a unique dynamic equilibrium. In the following section we show how wage inertia affects the transitional dynamics along this unique equilibrium. $^{12}$

\section{Numerical analysis}

When wages are flexible, transitional dynamics are governed by the diminishing returns to capital and, thus, they only depend on the initial value of capital per efficiency units of labor. In contrast, when there is wage inertia, transitional dynamics are governed by both the diminishing returns to capital and wage dynamics. In this case, transitional dynamics will depend on the initial conditions on both capital and wages per efficiency units of labor. The existence of two different forces driving the transition implies that the dynamic equilibrium will exhibit relevant differences with respect to the equilibrium path of a model with flexible wages. In this section, we compare these different transitional dynamics by means of a numerical analysis. Therefore, the value of the parameters must be fixed.

We assume that $\sigma=2$, which implies a value of the $I E S=0.5$, and $\alpha=0.35$, which implies a constant value of the labor income share equal to $65 \%$. We fix $x=2 \%$ and $n=1 \%$, which are within the range of empirically plausible values of these two

\footnotetext{
${ }^{12}$ Given that we have a two dimensional manifold, there are two roots with a negative real part. In the numerical example of the following section, the roots are complex numbers when $\theta$ is sufficiently low. This implies that for a sufficiently high intensity of wage inertia the equilibrium exhibits oscillations. In the examples in the following section, we assume a value of $\theta$ such that the roots are real numbers. Therefore, the non-monotonic behavior of the variables will just be a consequence of the existence of two different forces driving the transition.
} 
parameters. The depreciation rate $\delta=6.46 \%$ implies a long run net interest rate equal to $5.2 \%$ and the subjective discount rate $\rho=0.012$ implies that the long run ratio of capital to GDP equals 3. Given these values of the parameters, a period must be interpreted as a year. We assume that there is no unemployment benefit in the benchmark economy, $\lambda=0$, and the value of $\gamma$ is set so that the long run employment rate equals $l^{*}=0.9$. As $\gamma$ is used to calibrate the long run value of the employment rate, this parameter will take a different value in the economy with flexible wages and in the economy with wage inertia: specifically, $\gamma=1.22$ in the economy with wage inertia and $\gamma=1.11$ in the economy with flexible wages. Finally, the parameter $\theta$ determines the speed of wage adjustment. ${ }^{13}$ We set the value of $\theta$ equal to 0.2 , which implies that half distance in wages is satisfied in only three periods. ${ }^{14}$

In what follows, we show the results of several selected numerical exercises. In the numerical examples we use the relaxation algorithm proposed by Trimborn, Koch and Steger (2008) to obtain the transition in a two-dimensional stable manifold. The purpose of the exercises in Subsection 4.1 is to show that the model with wage inertia can explain some growth facts that the neoclassical growth model with flexible wages cannot explain. The exercises in Subsection 4.2 compare the growth effects of shocks in an economy with flexible wages and in an economy with wage inertia.

\subsection{Transitional dynamics}

In a first numerical exercise, Figure 1 compares the transitional dynamics of two economies with the same initial capital stock, which is $5 \%$ smaller than the long run capital stock, and a different initial wage. The economy described by the continuous line has an initial wage that is $5 \%$ lower than the long run wage and the economy illustrated by the dashed line has an initial wage that is $5 \%$ higher than its long run value. Without wage inertia, this initially small capital stock will imply a growth rate of GDP larger than $2 \%$ and monotonically decreasing towards its long run value. Therefore, this numerical exercise is aimed to show how wage inertia and the initial conditions on wages modify this transitional dynamics. The first two panels show the time path of the two state variables: wages and capital per efficiency units. The third panel shows the time path of the interest rate, which follows from (11). This equation implies a negative relationship between wages per efficiency units of labor and the interest rate over the growth process. Panel (iv) displays the time path of the employment rate. Equation (13) shows that the path of

\footnotetext{
${ }^{13}$ The value of $\theta$ could be calibrated using the autoregressive coefficient in the estimated wage equations. However, there is no consensus on the value of this coefficient in the empirical labor literature (see Montuenga and Ramos-Parreño, 2005). The value of the parameter $\theta$ used in the simulation exercises would imply a conservative value of the autoregressive coefficient equal to 0.82 .

${ }^{14}$ Half distance is defined as $\frac{\widehat{w}_{\tau}-\widehat{w}_{0}}{\widehat{w}^{*}-\widehat{w}_{0}}=\frac{1}{2}$, where $\tau$ is the number of periods needed to satisfy half distance.
} 
the employment rate is completely determined by the path of capital and wages per efficiency units of labor. As capital accumulates, labor demand increases and so does the employment rate. However, an increase in wages reduces the employment rate. Thus, the two forces driving the transition have opposite effects on employment, which may cause a non-monotonic behavior in the time path of this variable (see panel iv).

Panels v) and vi) display, respectively, the time path of the growth rate of per capita GDP and the logarithm of per capita GDP. We use the production function to obtain the logarithm of per capita GDP as the following function:

$$
\ln G D P=a+\alpha \ln k+(1-\alpha) \ln l+x t
$$

where $a$ is a constant. In the long run, the logarithm of GDP is a linear function of time implying a constant long run growth rate equal to $x$. However, during the transition, both the accumulation of capital and the growth of the employment rate determine the time path of the GDP growth rate. In the economy illustrated by the continuous line, the employment rate is initially high and suffers a process of fast reduction. The high employment rate explains the initially high level of per capita GDP, and the fast reduction in employment explains the initially low growth rate of GDP.

The dashed line in Figure 1 illustrates the transitional dynamics of an economy that has the same initial capital stock but an initially higher wage. The transitional dynamics of this economy are the opposite of the ones obtained in the economy with initially low wages. In particular, the growth rate of GDP decreases in the economy with initially high wages, whereas it increases in the other economy. We then conclude that economies with the same initial capital stock but different initial wages exhibit different time paths of the GDP growth rate. Therefore, the initial cost of labor per efficiency unit is relevant in explaining convergence, and its inclusion in a growth regression may improve the fit. ${ }^{15}$

In Figure 2, we compare two economies with the same initial conditions, but different assumptions on wage inertia. In the economy characterized by the continuous line we assume that $\theta=0.2$, whereas the dashed line shows the time path of the variables when there is no wage inertia, i.e. $\theta \rightarrow \infty$. In both economies the initial stock of capital per efficiency units of labor is $50 \%$ smaller than its long run value and the initial wage in the economy with wage inertia is set so that wages per efficiency unit in the initial period coincide in both economies. ${ }^{16}$ The main differences are in the time paths of the

\footnotetext{
${ }^{15}$ Note that measuring the initial cost of labor per efficiency units would require a measure of the level of efficiency units, which is not straightforward. To the best of our knowledge, the empirical growth literature has not introduced this variable in growth regressions.

${ }^{16}$ In the economy with flexible wages, the employment rate is fixed and equal to its long run value and wages are set in every period so that they are equal to the marginal product of labor. Therefore, in this case, the initial wage is determined by the initial marginal product of labor which, in turn, depends on the initial stock of capital. In the economy with wage inertia, wages depend on the past. In this case, the employment rate is set so that the marginal product of labor equals wages. This implies that the
} 
employment rate (panel iv) and of the growth rate of GDP (panel v). In the economy with flexible wages, the employment rate is constant and the transition of the growth rate is driven only by the diminishing returns to capital. In the economy with wage inertia, capital increases faster than wages in the initial periods, implying an increase in the employment rate. As a consequence, the reference wage increases, which accelerates the process of wage growth. This implies that the employment rate eventually decreases until it converges to its long run value. While the employment rate increases, the growth rate of GDP is larger than that of the economy with flexible wages, whereas it is smaller when the employment rate decreases. This implies a fast and sharp transition of the GDP growth rate in the economy with wage inertia. Note also that we can explain high values of the GDP growth rates with plausible values of the interest rate and of the intertemporal elasticity of substitution that cannot be explained when wages are flexible. King and Rebelo (1993) argue that the neoclassical growth model with plausible values of the interest rate cannot explain the large growth rates of East Asian economies during the period 1960-2000. We show that the introduction of wage inertia in this neoclassical growth model contributes to explaining the large GDP growth rate observed in emerging economies. ${ }^{17}$

Figure 3 illustrates the transitional dynamics of two economies with different initial conditions and different wage inertia. The continuous line shows the time path of the variables of an economy with wage inertia $(\theta=0.08)$, an initial capital stock per efficiency unit that is $25 \%$ smaller than its long run value, and an initial wage per efficiency unit that is $10 \%$ higher than its long run value. The dashed line shows the time path of the variables of an economy with flexible wages and an initial capital stock per efficiency unit that is $25 \%$ smaller than its long run value. In the economy with flexible wages, the employment rate is constant and equal to its long run value. Given that the stock of capital per efficiency unit is initially low, the interest rate will be high. This initially high interest rate causes a fast capital accumulation, which explains the increasing time path of wages per efficiency unit and the decreasing time path of the interest rate. The time path of the interest rate explains the time path of the growth rate, which is initially high and then, during the transition, decreases until it converges to its long run value. Thus, the growth rate exhibits a monotonic transition.

The economy with wage inertia exhibits a completely different transition. The initially

employment is not constant. Wages are a state variable and their initial value does not depend on the initial stock of capital. Therefore, the initial value of wages in the economy with wage inertia may not coincide with the initial value of wages in the economy without wage inertia. Indeed, they only coincide when the initial value of the employment rate in the economy with wage inertia coincides with its long run value. This occurs in Figure 2, but does not occur in Figure 3.

${ }^{17}$ In Figure 2, the average growth rate during the first 10 years is $4 \%$ when wages are flexible and $6 \%$ when wages exhibit inertia. The latter growth rate is closer to the growth rates exhibited by some emerging economies. 
high value of wages per efficiency unit implies that the initial value of both the employment rate and the interest rate are initially low. On the one hand, the low interest rate implies that capital per efficiency unit decreases in the initial periods. On the other hand, wages decrease because of the low employment rate. The reduction in wages causes employment to grow during the initial periods of the transition. In these initial periods, the growth in employment is partially compensated by the reduction in capital per efficiency unit, and thus the growth rate of GDP is low. During the transition, when capital starts accumulating and there is still employment growth, the GDP growth rate increases. Finally, the process of employment and capital growth ends, which implies a decrease in the growth rate of GDP. This explains the hump-shaped transition of the growth rate of GDP.

Easterly (1991), Christiano (1989) and, more recently, Steger (2001), Papageorgiou and Perez-Sebastian (2005) and Jeong and Yong Kim (2006, 2008) show that some fast growing economies exhibit a hump-shaped transition of the GDP growth rate during the development process. The neoclassical growth model with no wage inertia fails to show this type of transition. In this paper, we show that a version of the neoclassical growth model with wage inertia explains this non-monotonic transition as the result of labor market dynamics. Obviously, the model in this paper is too simple to be a serious theory of development. However, it suggests that labor market dynamics driven by wage inertia may be a relevant part of a development theory.

\subsection{Technological and fiscal policy shocks}

In this subsection we compare the transitional dynamics implied by two different technological shocks and a fiscal policy shock. In the figures, the continuous line illustrates the transitional dynamics in our benchmark economy with wage inertia and the dashed line shows the transitional dynamics of an economy with flexible wages. In the examples in this subsection we assume that the economies before the shock are initially in the steady state.

Figure 4 shows the transitional dynamics implied by a permanent technological shock that increases the level of TFP by $5 \%$. In the economy with flexible wages, this shock causes an initial increase in the interest rate. This increase implies that the capital stock per efficiency units of labor, after the initial reduction due to the increase in the efficiency units, increases during the transition. This explains both the increasing time path of wages per efficiency unit and the decreasing time path of the interest rate. Note that the time path of the interest rate explains both the initial increase in the GDP growth rate and also the decreasing time path of this variable during the transition. The effects of this shock are completely different in the economy with wage inertia. In this economy, the shock does not initially increase the wage. As a consequence, the wage per efficiency units 
of labor initially suffers a stronger reduction. This has two effects. First, the increase in the interest rate will be larger when there is wage inertia, implying a faster accumulation of capital. Second, the employment rate will initially jump upwards, as wages initially remain constant and the marginal product of labor increases. As a consequence, the average labor income of the economy increases. This causes the increase in wages per efficiency unit and the reduction in the employment rate during the transition. The reduction of employment has a negative effect on the growth rate of GDP. Thus, the growth rate of GDP will be driven by two different and opposite effects: the reduction in the employment rate and the increase in the capital stock. Given our assumption of low wage inertia, the employment rate will fall quickly, implying that this effect initially dominates the transition. This explains the reduction in the growth rate of GDP after the positive technological shock. Note that the growth effects of this technological shock are the opposite of the ones obtained when wages do not exhibit inertia. ${ }^{18}$

Figure 5 shows the transitional dynamics implied by a permanent technological shock that increases the exogenous growth rate from $2 \%$ to $3 \%$. In the economy with flexible wages, the employment rate is constant and the transitional dynamics will be governed only by the diminishing returns to capital. The growth rate increases along the transition until it converges to its new long run value. As explained in Proposition 3, this shock has permanent effects on the employment rate in the economy with wage inertia, as a consequence of the positive relationship between growth and employment introduced by wage inertia. Therefore, the employment rate increases until it converges to its new steady state. Obviously, this permanent effect on employment also implies permanent effects on the levels of GDP and capital that are not present when wages are flexible. As we said, this result is consistent with the empirical finding of the long run relationship between the rate of growth of total factor productivity and unemployment.

The purpose of presenting these two exercises is to show the relevant consequences of assuming wage inertia in understanding the short and long run effects of technological shocks. As an illustrative example, consider the productivity slowdown suffered by most western economies in the 1970s. If we interpret this slowdown as a permanent reduction of the exogenous growth rate, then, according to the flexible wage model, it will not have long run effects on the employment rate, whereas it will cause a permanent reduction in the employment rate in an economy with wage inertia. This suggests that the different long run effects on the labor market that this shock had in the European and US economies could be explained by a different intensity of wage inertia. Wages should exhibit strong wage inertia in European economies, whereas they should be (almost) flexible in the US.

Figure 6 shows the transitional dynamics implied by the introduction of an

\footnotetext{
${ }^{18}$ Danthine and Kurmann (2004) study the effects of a temporary technological shock in a model with wage inertia. Because of the differences in price rigidity and the definition of the social norm, the implied transitional dynamics are very different from the ones obtained in this paper.
} 
unemployment benefit, $\lambda=1 / 3$. This fiscal policy raises the current average labor income and thus increases wages. In the economy with flexible wages, this causes an initial jump upwards in wages per efficiency unit which has two different effects. On the one hand, the employment rate decreases, which implies a reduction in GDP. On the other hand, the interest rate decreases which causes the reduction of capital per efficiency units of labor during the transition. The reduction in the capital stock explains the lower growth rate during the transition. In the economy with wage inertia, wages do not jump after the introduction of the unemployment benefit. As a consequence, the interest rate does not initially decrease, nor does the employment rate. This implies that the level of GDP remains constant after the introduction of the unemployment benefit. However, during the initial periods of the transition, wages will experience a process of rapid growth that reduces both the interest rate and the employment rate. As a consequence, the stock of capital decreases during the transition. The combined effect of the reduction in the stock of capital per efficiency units of labor and in the employment rate explains the larger reduction in the growth rate and the time path of the log of per capita GDP. This example shows that wage inertia delays the effects of this fiscal policy, and the reduction in the GDP growth due to this fiscal policy will be larger. We conjecture that this conclusion could be generalized to any fiscal policy that affects the economy by increasing wages.

\section{Internal reference wage}

We have assumed that workers' disutility of effort depends on the comparison between the wage and an external reference wage, which is interpreted as a social norm. In this section, we will assume instead that the disutility of effort depends on the comparison between the wage and an internal reference wage which, according to Collard and de la Croix (2000), can be interpreted as a personal norm. We define this personal norm as $w_{t}^{p}$ and we assume that it depends on the past worker's labor income, as follows:

$$
w_{t}^{p}=w_{0}^{p} e^{-\theta t}+\theta \int_{0}^{t} e^{-\theta(t-i)} I^{p}(i) d i
$$

where $w_{0}^{p}$ is the initial value of the personal norm, $\theta>0$ provides a measure of the wage adjustment rate and $I_{t}^{p}$ is the worker's labor income

$$
I_{t}^{p}=(1-\tau) l_{t} w_{t}+\left(1-l_{t}\right) b_{t}
$$


where $w_{t}$ is the wage of the worker. ${ }^{19}$ For the sake of simplicity, we assume that there are no unemployment benefits, i.e. $b_{t}=0$. Differentiating with respect to time (25), we obtain the following differential equations governing the evolution of the personal norm:

$$
\dot{w}_{t}^{p}=\theta\left[(1-\tau) l_{t} w_{t}-w_{t}^{p}\right]
$$

Firms choose capital, labor and wages to maximize the discounted sum of profits subject to technology, the effort function, and equation (27). The latter equation implies that firms take into account that setting current wages today affects the future value of the personal norm. In contrast, this is not taken into account in the external reference wage model, as the social norm depends on the average wage of the economy and not on the worker's wage. This important difference means that in the internal reference wage model the firms' problem is a dynamic maximization problem. The maximization problem is solved in Appendix C. We show that effort is not constant in this case and that it satisfies the following differential equation:

$$
\frac{\dot{e}_{t}^{f}}{e_{t}^{f}}=\theta k_{t}\left(\frac{\widehat{w}_{t}}{1-\alpha}\right)^{-\frac{1}{\alpha}} \widetilde{\gamma} \exp \left(e_{t}^{f}\right)-\left[\theta-n+\alpha\left(\frac{\widehat{w}_{t}}{1-\alpha}\right)^{\frac{\alpha-1}{\alpha}}\right]\left(1-e_{t}^{f}\right) \text {, }
$$

where $\widehat{w}_{t}=w_{t} / A_{t} e_{t}^{f}$ is the ratio between wages and efficiency units of labor. In Appendix $\mathrm{C}$ we also show that the dynamic equation driving wages per efficiency unit of labor is

$$
\frac{\dot{\widehat{w}}_{t}}{\widehat{\widehat{w}}_{t}}=\left[\theta-n+\alpha\left(\frac{\widehat{w}_{t}}{1-\alpha}\right)^{\frac{\alpha-1}{\alpha}}\right]\left(1-e_{t}^{f}\right)^{2}+e_{t}^{f} \theta \widetilde{\gamma} \exp \left(e_{t}^{f}\right) k_{t}\left(\frac{\widehat{w}_{t}}{1-\alpha}\right)^{-\frac{1}{\alpha}}-\theta-x
$$

The system of differential equations (15), (16), (28), and (29) characterizes the dynamic equilibrium. The equilibrium is characterized by two state variables $\left(k_{t}\right.$ and $\left.\widehat{w}_{t}\right)$ and two control variables $\left(c_{t}\right.$ and $\left.e_{t}^{f}\right)$. The steady state values of the two state variables and consumption coincide with the steady state of those variables in the economy with an external reference wage; the long run level of effort is

$$
e^{f^{*}}=1-\frac{\theta+x}{\theta-n+\delta+\rho+\sigma x}<1
$$

and the long run employment rate is

$$
l^{*}=\frac{\theta+x}{\theta \widetilde{\gamma} \exp \left(e^{f^{*}}\right)}=\left(\frac{\theta+x}{\theta \gamma}\right) \exp \left(1-e^{f^{*}}\right),
$$

\footnotetext{
${ }^{19}$ If the worker is employed he obtains $I_{t}^{e}=(1-\tau) w_{t}-m_{t}$ and if he is unemployed obtains $I_{t}^{u}=b_{t}+\frac{m_{t}}{1-l_{t}}-m_{t}$, where $m_{t}$ is the cost of the unemployment insurance. Complete insurance implies that $m_{t}=\left(1-l_{t}\right)\left((1-\tau) w_{t}-b_{t}\right)$ and then $I_{t}^{e}=I_{t}^{u}=I_{t}^{p}=(1-\tau) w_{t} l_{t}+\left(1-l_{t}\right) b_{t}$ where $w_{t}$ is the wage of the worker.
} 
where $\gamma=\widetilde{\gamma} \exp (1)$. From the comparison with the economy with an external reference wage it follows that the long run level of effort is smaller, while the long run employment rate is higher. ${ }^{20}$ This is a consequence of the fact that in the internal reference wage model firms set lower wages in order to reduce the future value of the reference wage. ${ }^{21}$ This explains the larger employment rate and the lower effort level.

From the numerical comparison between the external and internal reference wage economies, we show that the time paths of the variables in both models are almost identical, with the notable exception of the GDP growth rate. ${ }^{22}$ The reason is that this variable depends directly on the time path of effort, which is not constant in the internal reference wage model. To see this, note that using the production function we obtain that the logarithm of per capita GDP is

$$
\ln G D P=a+\alpha \ln k+(1-\alpha) \ln l+(1-\alpha) e+x t
$$

where $a$ is a constant. Note that the time path of the GDP growth rate depends on the time path of effort during the transition. Thus, the non-constant time path of effort in the internal reference wage model directly affects the time path of the GDP growth rate: an increasing (decreasing) time path of effort increases (decreases) the GDP growth rate, which will be higher (lower) than the one obtained in the external reference wage model. As an example of this, Figure 7 compares the time path of several variables in the economy with an internal reference wage (continuous line) and with an external reference wage (dashed line). We assume the same parameter values than in Figure 1, the initial capital stock and the initial wage are $5 \%$ smaller than their long run value. The time path of all the variables is very similar except for the time paths of effort and of the GDP growth rate. The increasing time path of effort in the internal reference wage model implies that the GDP growth rate will be initially larger than the GDP growth rate in the external reference wage model. However, the transition of the GDP growth rate is from below in both cases and opposite to the transition in the model with flexible wages, which is from above as capital increases during the transition. We conclude that in both cases transitional dynamics depend on the initial value of wages and thus may be very different from the ones obtained in the model with flexible wages. This conclusion is also illustrated in Figure 8, where we compare the internal and external reference wage models considering the numerical example of Figure 3. In this example, effort is declining in the

\footnotetext{
${ }^{20}$ To make the comparison, note that the long run employment rate in the external reference wage economy equals $l^{*}=(\theta+x) / \theta \gamma$ when $\lambda=0$.

${ }^{21}$ The long run value of wages per efficiency unit of labor coincides in both economies; i.e. $w^{i} / A e^{f^{*}}=$ $w^{e} / A$ where $w^{i}$ is the wage level in the internal reference economy and $w^{e}$ is the wage level in the external reference economy. As $e^{f^{*}}<1$, it follows that $w^{i}<w^{e}$.

${ }^{22}$ To simplify the comparison, we assume that $\gamma=\widetilde{\gamma} \exp (1)$ in the external reference wage model and $\gamma=\widetilde{\gamma} \exp \left(e^{f^{*}}\right)$ in the internal reference wage economy. Using this different parametrization, the long run values of the variables coincide in both models with the exception of effort.
} 
internal reference wage model, which implies that the GDP growth rate in this case is initially lower than in the external reference wage model. However, the time path of the GDP growth rate is still hump-shaped in the internal reference wage case. Therefore, the main conclusions regarding the effects of wage inertia on the transitional dynamics of the GDP growth rate hold when the reference wage is internal instead of external.

\section{Conclusions}

In this paper we develop a version of the neoclassical growth model with wage inertia. We use this model to compare the equilibrium with wage inertia with the equilibrium of an economy with flexible wages. We show that these economies exhibit very different transitional dynamics.

We study the transitional dynamics using selected numerical exercises. In the first exercise, we show that economies with the same initial capital stock may exhibit opposite transitions of the GDP growth rates because of different values of the initial wage. In the second and third exercises, we compare the transitional dynamics in an economy with wage inertia and in an economy with flexible wages. In the economy with flexible wages, the time path of the macroeconomic variables exhibits a monotonic behavior, while we show that this time path can be non-monotonic when wage inertia is introduced. We argue that this non-monotonic transition is a consequence of the interaction between two forces: diminishing returns to capital and the process of wage adjustment. We show that this non-monotonic transition may explain both the initially high growth rates and also the hump-shaped transitions of the GDP growth rate that some emerging economies have exhibited in recent decades. This suggests that a closer analysis of labor market dynamics when wages exhibit inertia could explain some facts of the development process.

In the following two exercises we study the transitional dynamics implied by two different technological shocks: a permanent increase in the level of TFP and a permanent increase in the TFP growth rate. We show that the effects of the first shock on the growth rate of GDP will be the opposite if wage inertia is introduced. We also show that the second shock only has permanent effects on employment and on the level of GDP when wages exhibit inertia. We conclude that wage inertia crucially changes the effects of technological shocks. Finally, in a last numerical exercise, we show that the effects of fiscal policy depend on the intensity of wage inertia.

The introduction of wage inertia does not modify the long run GDP growth rate because it is exogenous in this model. The aim of future research is to extend this analysis of wage inertia to endogenous growth models. In these models, the long run growth rate of GDP is endogenously determined by the fundamentals of the economy and therefore it may depend on the intensity of wage inertia. 


\section{References}

[1] Akerlof, G. 1982. Labor contracts as partial gift exchange. Quarterly Journal of Economics. 97, 543-569.

[2] Alexopoulos, M., 2003. Growth and unemployment in a shirking efficiency wage model. Canadian Journal of Economics. 36 (3) 728-746.

[3] Basu, S., Fernald, J. And M. Kimball., 2006. Are technology improvements contractionary? American Economic Review. 96, 1418-1448.

[4] Beissinger, T. and Egger, H., 2004. Dynamic wage bargaining if benefits are tied to individual wages. Oxford Economic Papers. 56, 437-460.

[5] Bell, B., 1996. Wage curve or Phillips curve? Mimeo, Nuffield College, University of Oxford.

[6] Benassy, J.P., 1997. Imperfect Competition, Capital Shortages and Unemployment Persistence. Scandinavian Journal of Economics. 99, 15-27.

[7] Benigno, P., Ricci, L.A. and Surico, P., 2011. Unemployment and Productivity in the Long Run: the Role of Macroeconomic Volatility, Unpublished manuscript.

[8] Bewley, T.F., 2002. Fairness, Reciprocity, and Wage Rigidity. Cowles Foundation Discussion Paper. 1383.

[9] Blanchard, O. and Katz, L., 1997. What do we know and we do not know about the natural rate of unemployment. Journal of Economic Perspectives. 11, 51-73.

[10] Blanchard, O. and Katz, L.F., 1999. Wage Dynamics: Reconciling Theory and Evidence. NBER Working Paper. 6924.

[11] Blanchard, O. and Galí, J., 2007. Real wage rigidities and the new keynesian model. Journal of Money, Credit and Banking. 39, 35-65.

[12] Blanchard, O.J. and Wolfers J. , 2000. The Role of Shocks and Institutions in the Rise of European Unemployment: The Aggregate Evidence. The Economic Journal. 110, C1-C33.

[13] Braüninger, M., 2000. Wage Bargaining, Unemployment and Growth. Journal of Institutional and Theoretical Economics. 156/4, 646-660.

[14] Brecher, R., Chen, Z. and Choudhri, E., 2002. Unemployment and growth in the long run: an efficiency-wage model with optimal savings. International Economic Review. $43,875-894$. 
[15] Burkhardm, H. and Morgenstern, A., 2000. Indexation of unemployment benefits to previous earning, employment and wages. Munich Discussion Paper. 2000-13.

[16] Collard, F. and de la Croix, D., 2000. Gift Exchange and the Business Cycle: The Fair Wage Strikes Back. Review of Economic Dynamics. 3, 166-193.

[17] Christiano, L., 1989. Understanding Japan's Saving Rate: The Reconstruction Hypothesis. Federal Reserve Bank of Minneapolis Quarterly Review. 1322.

[18] De la Croix, D., de Walque, G. and Wouters, R., 2009. A note on inflation persistence in a fair wage model of the business cycle. Macroeconomic Dynamics. 13, 673-684.

[19] Danthine, J.P. and Donaldson, J.B., 1990. Efficiency wages and the business cycle puzzle. European Economic Review. 34, 1275-1301.

[20] Danthine, J.P. and Kurmann, A., 2004. Fair wages in a New Keynesian model of the Business cycle. Review of Economic Dynamics. 7, 107-142.

[21] Daveri, F. and Mafezzoli, M., 2000. A numerical approach to fiscal policy, unemployment and growth in Europe, unpublished manuscript.

[22] Daveri, F. and Tabellini, G., 2000. Unemployment and Taxes. Economic Policy. 5: 49-104.

[23] Doménech, R. and García, J.R., 2008. Unemployment, taxation and public expenditure in OECD economies. European Journal of Political Economy. 24, 202217.

[24] Easterly, W., 1991. Economic Stagnation, Fixed Factors, and Policy Thresholds. World Bank working paper. 795.

[25] Greiner, A. and Flaschel, P., 2010. Public debt and public investment in an endogenous growth model with real wage rigidities. Scottish Journal of Political Economy. 57, 68-82.

[26] Jeong, H. and Kim, Y., 2006. S-shaped Transition and Catapult Effects, unpublished manuscript.

[27] Jeong, H. and Kim, Y., 2008. Complementarity and Transition to Modern Economic Growth, unpublished manuscript.

[28] King, R. and Rebelo, S., 1993. Transitional dynamics and economic growth in the neoclassical model. American Economic Review. 83 (4), 908-931. 
[29] Layard, P.R.J., S.J. Nickell and Jackman R., 1991. Unemployment: Macroeconomic Performance and the Labor Market Oxford: Oxford University Press.

[30] Mafezzoli, M., 2001. Non-Walrasian Labor Markets and Real Business Cycles. Review of Economic Dynamics. 4, 860-892.

[31] Meckl, J., 2004. Accumulation of technological knowledge, wage differentials, and unemployment. Journal of Macroeconomics. 26, 65-82.

[32] Montuenga-Gómez, V. and Ramos-Parreño, J.M., 2005. Reconciling the wage curve and the Phillips curve. Journal of Economic Surveys. 19, 735-765.

[33] Nakajima, T., 2006. Unemployment and indeterminacy. Journal of Economic Theory. $126,314-327$.

[34] Papageorgiou, C. and Perez-Sebastian, F., 2006. Dynamics in a non-scale R\&D growth model with human capital: Explaining the Japanese and South Korean development experiences. Journal of Economic Dynamics and Control. 30, 901-930

[35] Pierpaolo, C., 2010. A Shumpeterian growth model with equilibrium unemployment. Metroeconomica. 61, 398-426.

[36] Raurich X., Sala, H. and Sorolla, V., 2006. Unemployment, Growth and Fiscal Policy, New Insights on the Hysteresis Hypothesis. Macroeconomic Dynamics. 10, 285-316.

[37] Steger, T.M., 2001. Stylized facts of economic growth in developing countries. Discussion Paper 08/2001.

[38] Trimborn, T., Koch, K.J. and Steger, T.M., 2008. Multidimensional transitional dynamics: a simple numerical procedure. Macroeconomic Dynamics. 12, 301-319.

[39] Van Schaik, B.T.M. and De Groot, H.L.F., 1998. Unemployment and endogenous growth. Labour 12, 189-219. 


\section{A System of Differential equations}

Using (23) and (24), we obtain that $\sigma\left(c_{t} A_{t}\right)=\sigma, \tilde{k}\left(\widehat{w}_{t}\right)=\left(\widehat{w}_{t} /(1-\alpha)\right)^{\frac{1}{\alpha}}, f^{\prime}\left[\tilde{k}\left(\widehat{w}_{t}\right)\right]=$ $\alpha\left(\widehat{w}_{t} /(1-\alpha)\right)^{\frac{\alpha-1}{\alpha}}, l_{t}=k_{t}\left(\widehat{w}_{t} /(1-\alpha)\right)^{-\frac{1}{\alpha}}$, and $h\left[\tilde{k}\left(\widehat{w}_{t}\right)\right]=\left(\widehat{w}_{t} /(1-\alpha)\right)^{\frac{\alpha-1}{\alpha}}$. Therefore, the system of differential equations characterizing the equilibrium with wage inertia, (15), (16), and (22), simplifies as follows:

$$
\begin{gathered}
\frac{\dot{c}_{t}}{c_{t}}=\frac{\alpha\left(\frac{\widehat{w}_{t}}{1-\alpha}\right)^{\frac{\alpha-1}{\alpha}}-\delta-\rho-\sigma x}{\sigma}, \\
\frac{\dot{k}_{t}}{k_{t}}=\left(\frac{\widehat{w}_{t}}{1-\alpha}\right)^{\frac{\alpha-1}{\alpha}}-\frac{c_{t}}{k_{t}}-(n+x+\delta),
\end{gathered}
$$

and

$$
\frac{\dot{\widehat{w}}_{t}}{\widehat{w}_{t}}=\theta\left(\gamma(1-\lambda) k_{t}\left(\frac{\widehat{w}_{t}}{1-\alpha}\right)^{-\frac{1}{\alpha}}+\gamma \lambda-1\right)-x .
$$

If wages are flexible then $l_{t}=\bar{l}$. In this case, from (13), we obtain that the wage is the following function of capital: $\widehat{w}_{t}=(1-\alpha)\left(k_{t} / \bar{l}\right)^{\alpha}$. Note that this implies that capital is the only state variable and the system of differential equations characterizing the equilibrium, (15) and (16), simplify as follows:

$$
\frac{\dot{c}_{t}}{c_{t}}=\frac{\alpha\left(\frac{k_{t}}{\bar{l}}\right)^{\alpha-1}-\delta-\rho-\sigma x}{\sigma},
$$

and

$$
\frac{\dot{k}_{t}}{k_{t}}=\left(\frac{k_{t}}{\bar{l}}\right)^{\alpha-1}-\frac{c_{t}}{k_{t}}-(n+x+\delta) .
$$

\section{B Proof of Proposition 4}

The Jacobian matrix associated to (A1), (A2) and (A3) is

$$
\begin{aligned}
J= & \left(\begin{array}{lll}
\frac{\partial \dot{w}_{t}}{\partial w_{t}} & \frac{\partial \dot{w}_{t}}{\partial k_{t}} & \frac{\partial \dot{w}_{t}}{\partial c_{t}} \\
\frac{\partial \dot{k}_{t}}{\partial w_{t}} & \frac{\partial \dot{k}_{t}}{\partial k_{t}} & \frac{\partial \dot{k}_{t}}{\partial c_{t}} \\
\frac{\partial \dot{c}_{t}}{\partial w_{t}} & \frac{\partial \dot{c}_{t}}{\partial k_{t}} & \frac{\partial \dot{c}_{t}}{\partial c_{t}}
\end{array}\right) \\
= & \left(\begin{array}{ccc}
-\theta(1-\lambda) \gamma\left(\frac{k^{*}}{\alpha}\right)\left(\frac{w^{*}}{1-\alpha}\right)^{-\frac{1}{\alpha}} & \gamma \theta(1-\lambda)\left(\frac{w^{*}}{1-\alpha}\right)^{-\frac{1}{\alpha}} w^{*} & 0 \\
-\left(\frac{1}{\alpha}\right)\left(\frac{w^{*}}{1-\alpha}\right)^{\frac{-1}{\alpha}} k^{*} & \frac{c^{*}}{k^{*}} & -1 \\
-\left(\frac{w^{*}}{1-\alpha}\right)^{\frac{-1}{\alpha}} c^{*} & 0 & 0
\end{array}\right)
\end{aligned}
$$


The characteristic polynomial is

$$
P(J)=-\mu^{3}+\mu^{2} \operatorname{Tr}(J)+\mu H+\operatorname{Det}(J),
$$

where $\operatorname{Tr}(J)$ is the trace of the Jacobian matrix, the determinant is

$$
\operatorname{Det}(J)=\gamma \theta(1-\lambda)\left(\frac{w^{*}}{1-\alpha}\right)^{-\frac{2}{\alpha}} w^{*} c^{*}>0
$$

and

$$
\begin{aligned}
H & =\frac{\partial \dot{k}_{t}}{\partial w_{t}} \frac{\partial \dot{w}_{t}}{\partial k_{t}}-\frac{\partial \dot{w}_{t}}{\partial w_{t}} \frac{\partial \dot{k}_{t}}{\partial k_{t}}= \\
& =\theta(1-\lambda) \gamma\left(\frac{k^{*}}{\alpha}\right)\left(\frac{w^{*}}{1-\alpha}\right)^{\frac{-1}{\alpha}}[\rho+(\sigma-1) x-n]>0
\end{aligned}
$$

where the inequality follows from the bounded utility condition. Given that $H>0$ and $\operatorname{Det}(J)>0$, the equilibrium is saddle path stable regardless of the sign of the trace.

\section{Internal reference wage}

When the reference wage is based on a personal norm, the profit maximization problem of the firms is

$$
\begin{gathered}
\operatorname{Max} \int_{0}^{\infty} \exp (-R(t))\left\{F\left(K_{t}, e_{t}^{f}\left(w_{t}, w_{t}^{p}\right) A_{t} L_{t}\right)-r_{t} K_{t}-w_{t} L_{t}\right\} d t \\
\text { s.t. } \\
\dot{w}_{t}^{p}=\theta\left[(1-\tau) l_{t} w_{t}-w_{t}^{p}\right]
\end{gathered}
$$

where $R(t)=\int_{\tau=0}^{t} r(\tau) d \tau$ and

$$
e_{t}^{f}\left(w_{t}, w_{t}^{p}\right)=\ln \left[(1-\tau) w_{t}\right]-\ln \left(\widetilde{\gamma} w_{t}^{p}\right) .
$$

The Hamiltonian is

$$
H=\exp (-R(t))\left\{F\left(K_{t}, e_{t}^{f}\left(w_{t}, w_{t}^{p}\right) A_{t} L_{t}\right)-r_{t} K_{t}-w_{t} L_{t}\right\}+\mu_{t} \theta\left[(1-\tau) l_{t} w_{t}-w_{t}^{p}\right]
$$


and the first order conditions with respect to capital, labor, wages and the reference wage are

$$
\begin{gathered}
r_{t}=F_{1} \\
w_{t}=e_{t}^{f} A_{t} F_{2} \\
\exp (-R(t))\left[\frac{F_{2} A_{t} L_{t}}{w_{t}}-L_{t}\right]+\mu_{t} \theta(1-\tau) l_{t}=0 \\
\exp (-R(t)) \frac{F_{2} A_{t} L_{t}}{w_{t}^{p}}+\mu_{t} \theta=\dot{\mu}_{t}
\end{gathered}
$$

Combining (C4) and (C5), we obtain

$$
1-\frac{1}{e_{t}^{f}}=\mu_{t} \frac{\theta(1-\tau) l_{t}}{L_{t}} \exp (R(t))
$$

We log-differentiate with respect to time (C7) to obtain

$$
-\frac{\dot{e}_{t}^{f}}{e_{t}^{f}\left(1-e_{t}^{f}\right)}=\frac{\dot{\mu}_{t}}{\mu_{t}}-n+r(t) .
$$

From combining (C4), (C5), (C6), and (C2) we obtain

$$
\theta l_{t} \widetilde{\gamma} \exp \left(e_{t}^{f}\right)\left(\frac{1}{e_{t}^{f}-1}\right)+\theta=\frac{\dot{\mu}_{t}}{\mu_{t}}
$$

We combine (C8) and (C9) to obtain

$$
-\frac{\dot{e}_{t}^{f}}{e_{t}^{f}}=[\theta-n+r(t)]\left(1-e_{t}^{f}\right)-\theta l_{t} \widetilde{\gamma} \exp \left(e_{t}^{f}\right) .
$$

From (C2), we also obtain that

$$
\frac{\dot{w}_{t}}{w_{t}}=\dot{e}_{t}^{f}+\frac{\dot{w}_{t}^{p}}{w_{t}^{p}}
$$

where the growth rate of $w_{t}^{p}$ is obtained from combining $(\mathrm{C} 1)$ and $(\mathrm{C} 2)$

$$
\frac{\dot{w}_{t}^{p}}{w_{t}^{p}}=\theta\left[l_{t} \widetilde{\gamma} \exp \left(e_{t}^{f}\right)-1\right]
$$

We define wages per efficiency unit of labor and capital per efficiency unit of labor taking into account effort, i.e. $\widehat{w}_{t}=w_{t} / A_{t} e_{t}^{f}$ and $\widehat{k}_{t}=K_{t} / A_{t} e_{t}^{f} L_{t}$. Then, from (C4) and $(24)$, we obtain that $\tilde{k}\left(\widehat{w}_{t}\right)=\left(\widehat{w}_{t} /(1-\alpha)\right)^{\frac{1}{\alpha}}$ and the equations driving the growth of consumption per efficiency unit of labor $(c=C / A)$ and capital per efficiency unit of labor $(k=K / A N)$ are (A1) and (A2). We log-differentiate the definition of $\widehat{w}_{t}$ and we 
use (C11), (C10) and (C12) to obtain

$$
\frac{\widehat{\widehat{w}}_{t}}{\widehat{w}_{t}}=e_{t}^{f} l_{t} \theta \widetilde{\gamma} \exp \left(e_{t}^{f}\right)-\theta+[\theta-n+r(t)]\left(1-e_{t}^{f}\right)^{2}-x
$$

where $r(t)=\alpha\left(\widehat{w}_{t} /(1-\alpha)\right)^{\frac{\alpha-1}{\alpha}}$ and $l_{t}=k_{t} / \widehat{k}_{t}=k_{t}\left(\widehat{w}_{t} /(1-\alpha)\right)^{-\frac{1}{\alpha}}$. We substitute these expressions in equations (C10) and (C13) to obtain (28) and (29). 


\section{Figures}

Figure 1. Transitional dynamics: different initial conditions
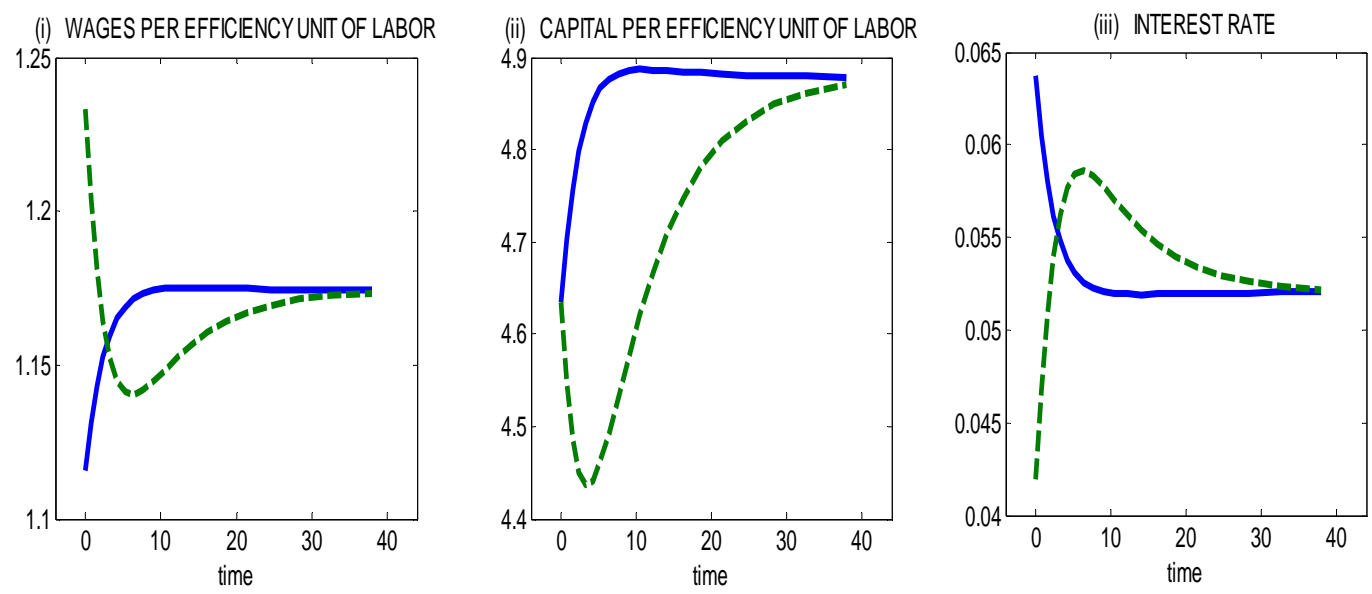

(iv) EMPLOYMENTRATE

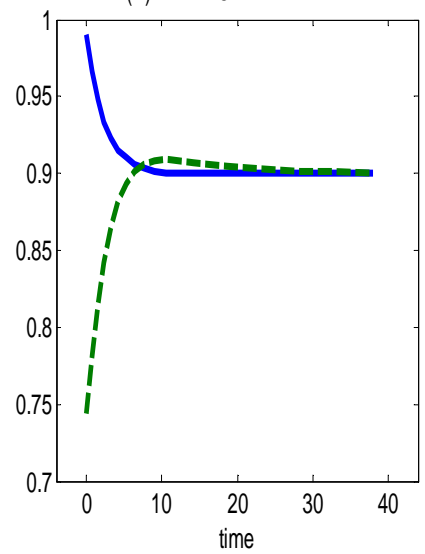

(v) GROWTHRATE

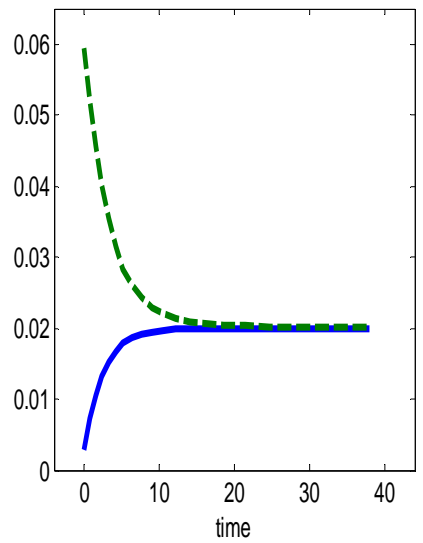

(vi) LOG GDP

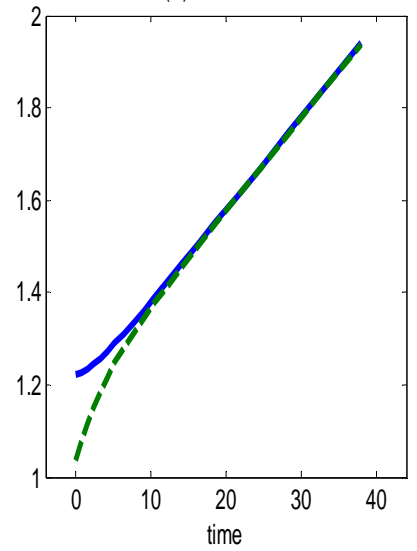

Note. Continuous lines display the transition when $k_{0}=0.95 k^{*}$ and $\hat{w}_{0}=0.95 \hat{w}^{*}$. Dashed lines display the transition when $k_{0}=0.95 k^{*}$ and $\hat{w}_{0}=1.05 \hat{w}^{*}$. 
Figure 2. Transitional dynamics: different wage inertia
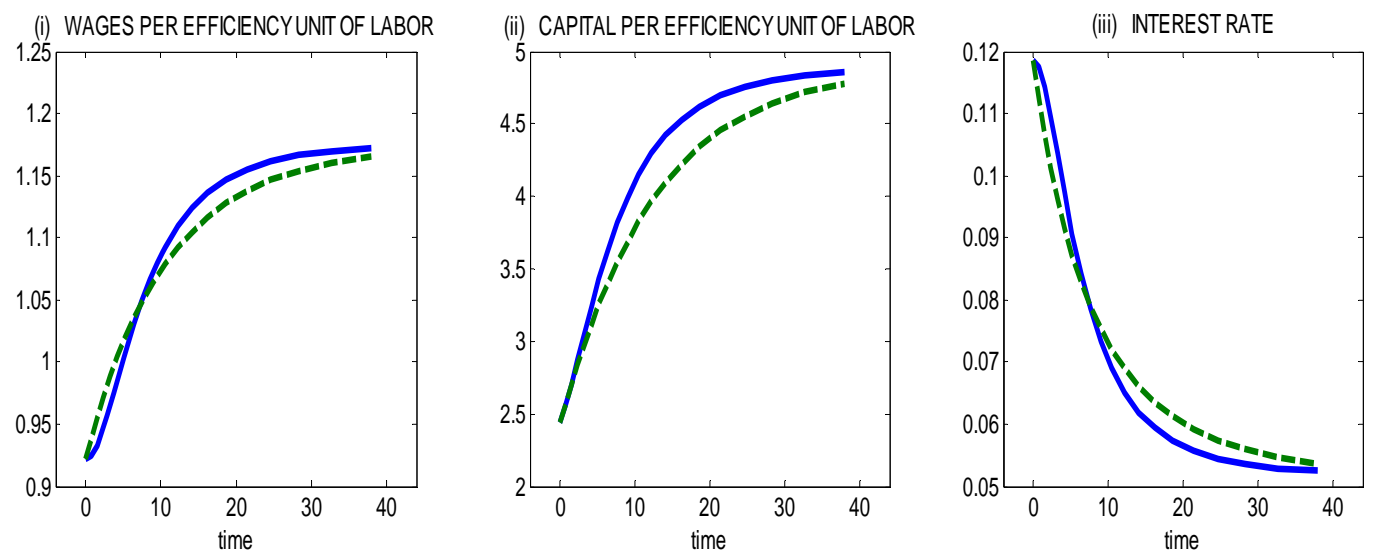

(iv) EMPLOYMENTRATE
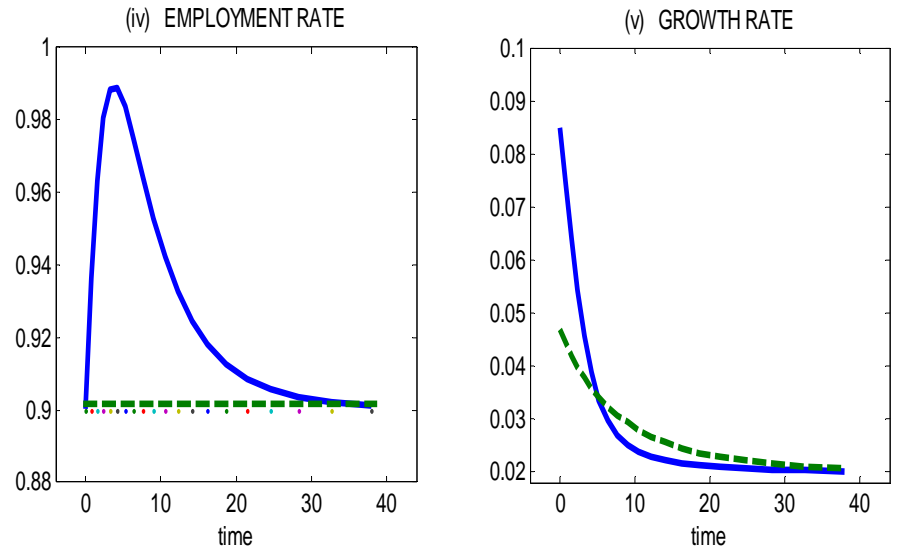

(vi) LOG GDP

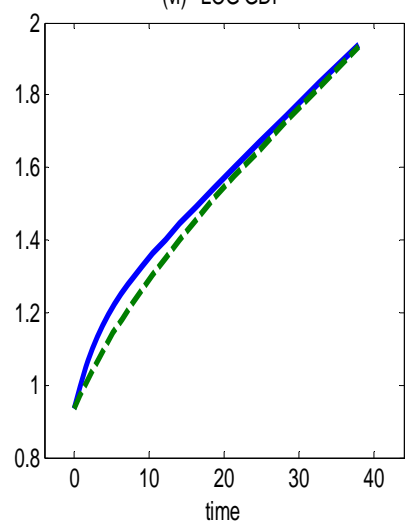

Note. Continuous lines display the transition of an economy with wage inertia and $k_{0}=0.5 k^{*}$. Dashed lines display the transition of an economy with flexible wages and $k_{0}=0.5 k^{*}$. 
Figure 3. Transitional dynamics: different wage inertia and initial conditions
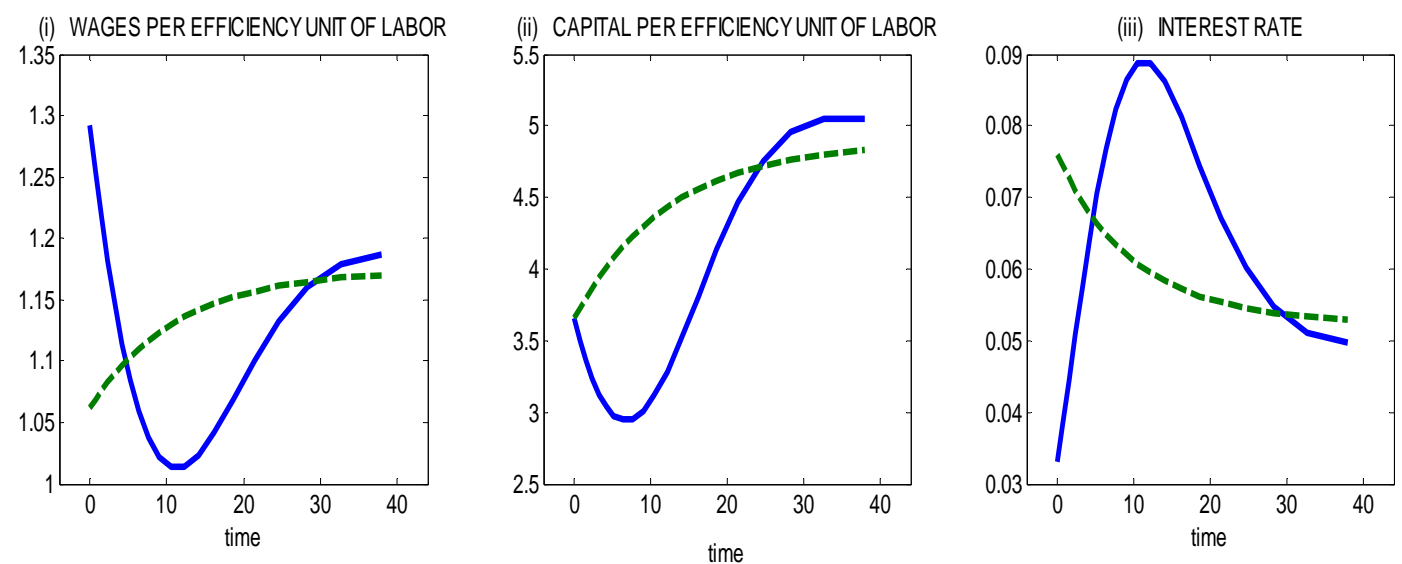

(iv) EMPLOYMENT RATE

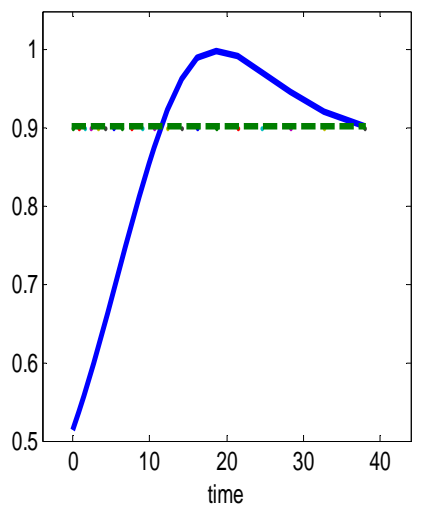

(v) GROWTHRATE

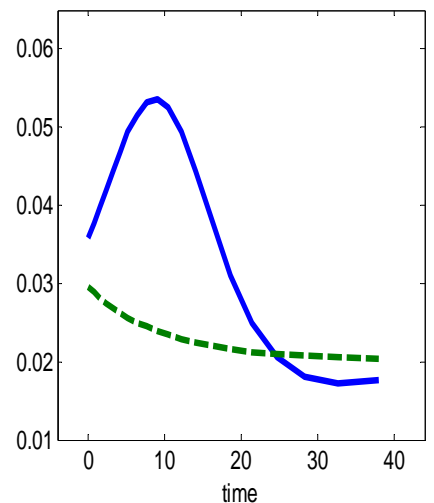

(vi) LOG GDP

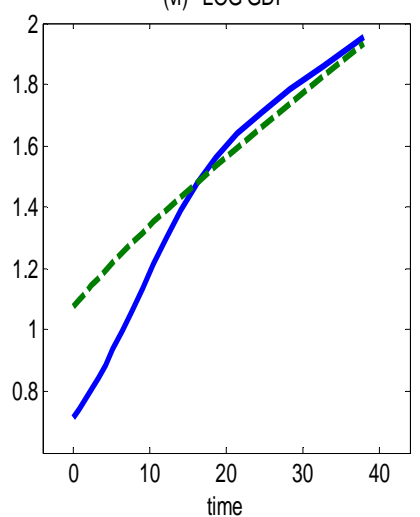

Note. Continuous lines display the transition of an economy with wage inertia, $k_{0}=0.75 k^{*}$ and $\hat{w}_{0}=1.1 \hat{w}^{*}$. Dashed lines display the transition of an economy with flexible wages and $k_{0}=0.75 k^{*}$. 
Figure 4. Permanent increase in the level of TFP
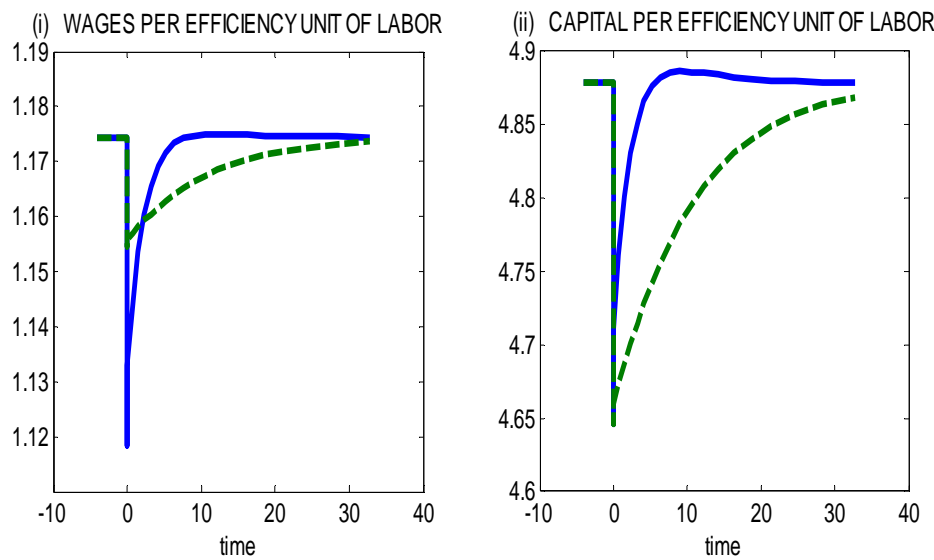

(iii) INTEREST RATE

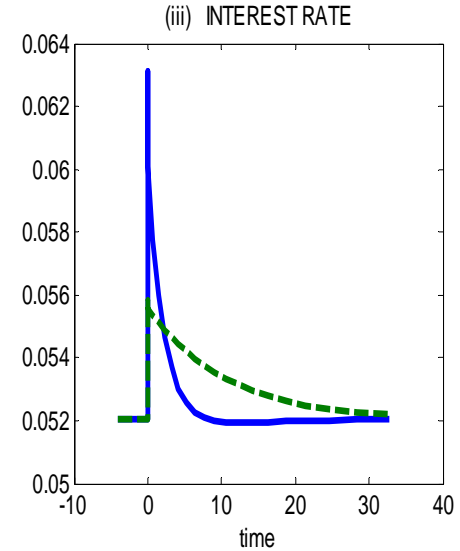

(iv) EMPLOYMENT RATE
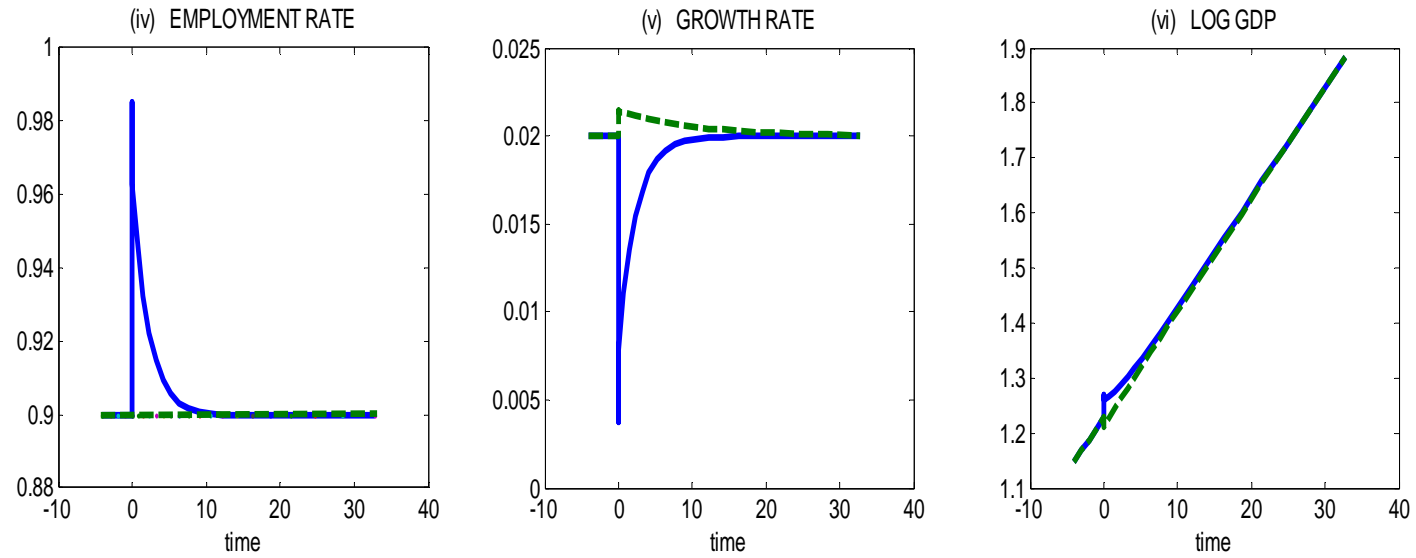

Note. Both lines display the transition implied by a permanent $5 \%$ increase in the level of TFP. Continuous (dashed) lines show the transition of an economy with wage inertia (flexible wages). 
Figure 5. Permanent increase in the long run growth rate
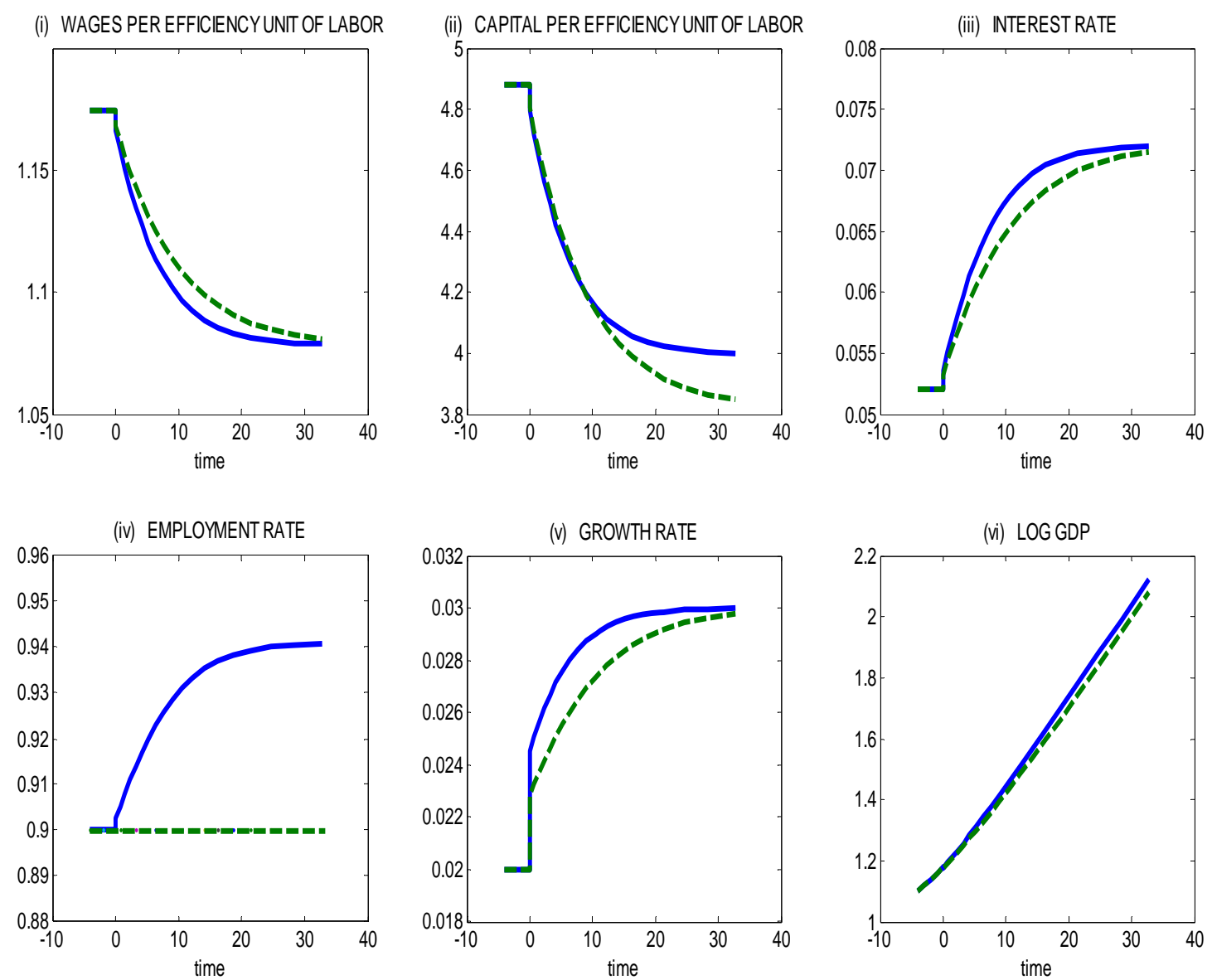

(vi) LOG GDP

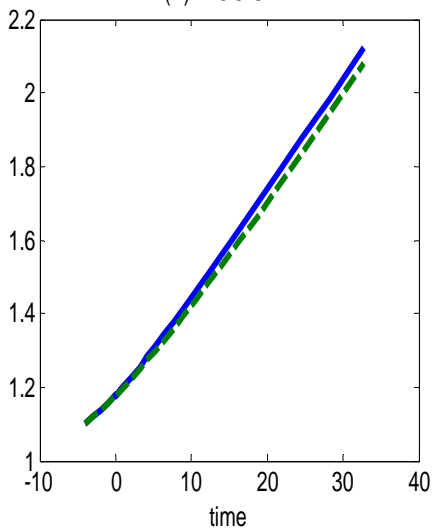

Note. Both lines display the transition implied by a permanent increase in the growth rate of TFP. Continuous (dashed) lines show the transition of an economy with wage inertia (flexible wages). 
Figure 6. Unemployment benefit
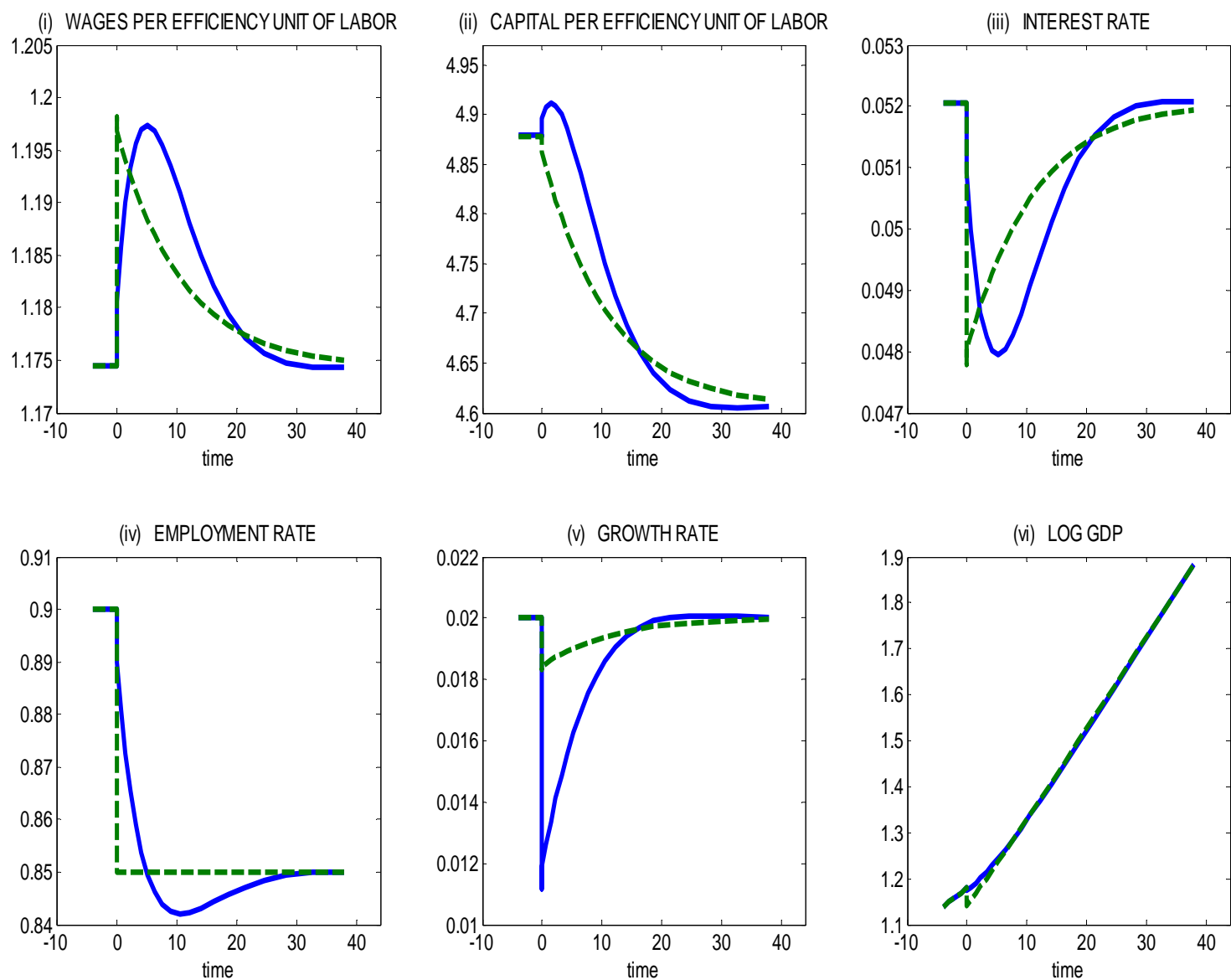

(vi) LOG GDP

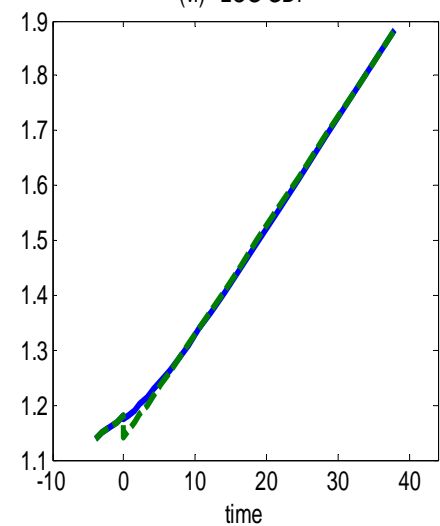

Note. Both lines display the transition implied by the introduction of an unemployment benefit $(\lambda=1 / 3)$. Continuous (dashed) lines show the transition of an economy with wage inertia (flexible wages). 
Figure 7. Comparison personal and social norm. Transitional Dynamics I
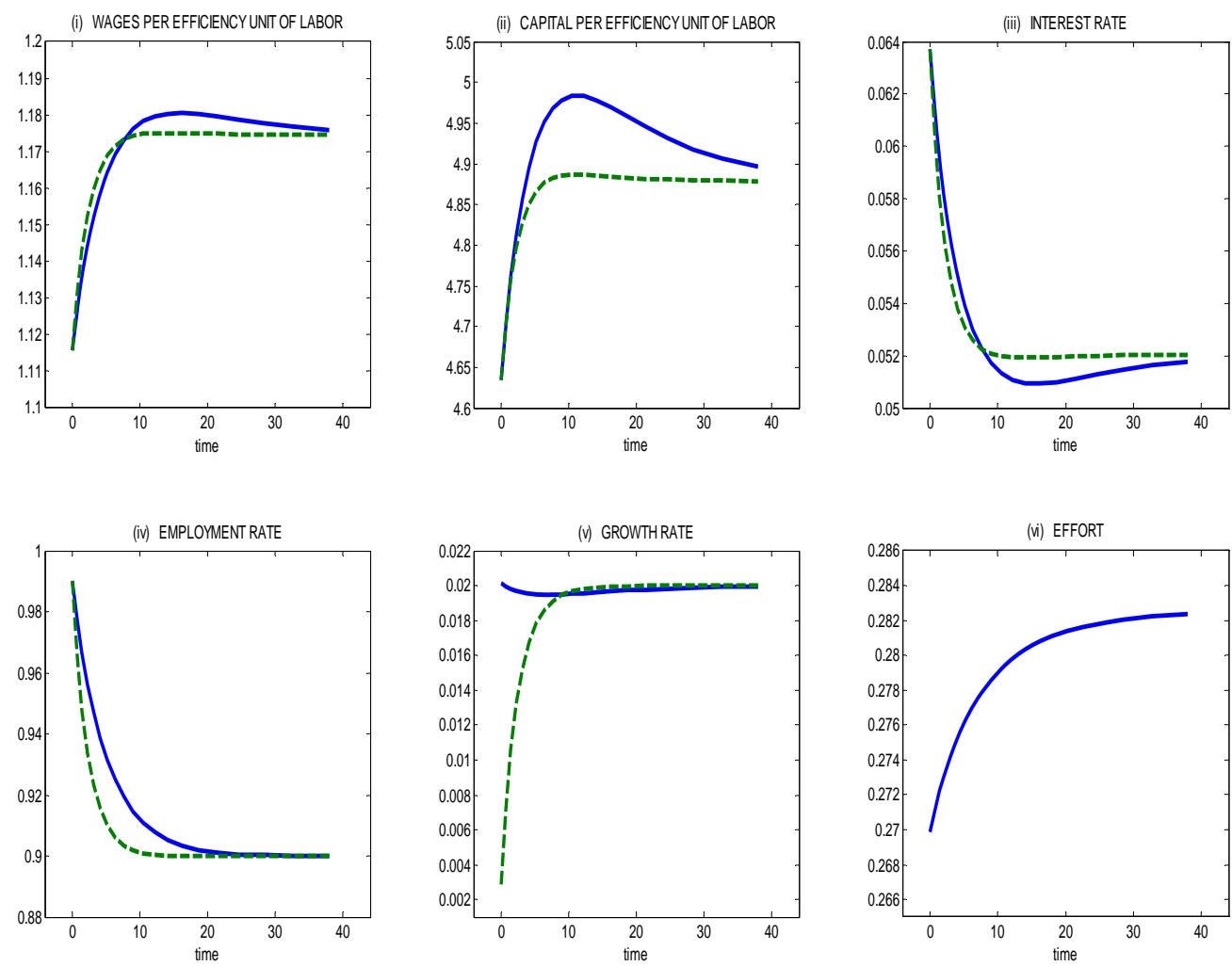

Note. Both lines display the transition of economies with wage inertia and the following initial conditions: $k_{0}=0.95 k^{*}$ and $\hat{w}_{0}=0.95 \hat{w}^{*}$. Continuous (dashed) lines show the transition of an economy with an internal (external) reference wage. 
Figure 8. Comparison personal and social norm. Transitional Dynamics II
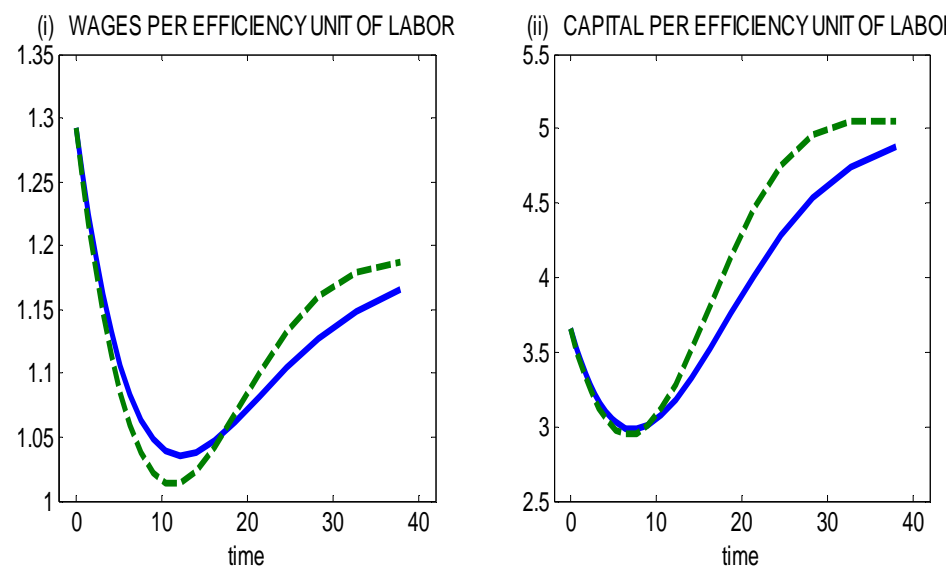

(iii) INTERESTRATE

(iv) EMPLOYMENTRATE

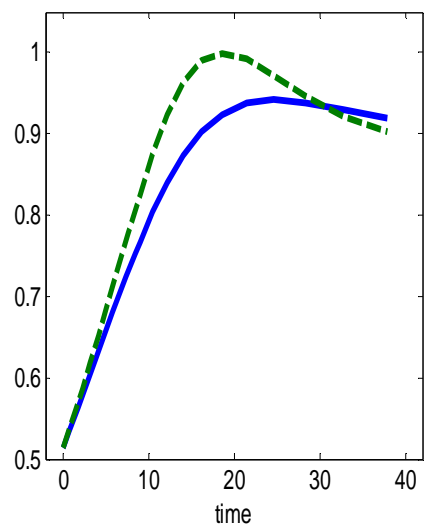

(v) GROWTHRATE

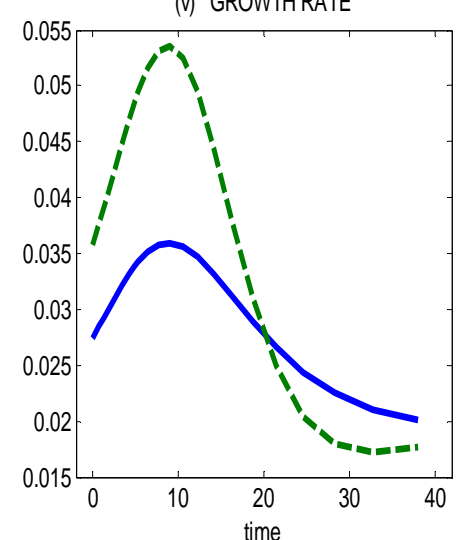

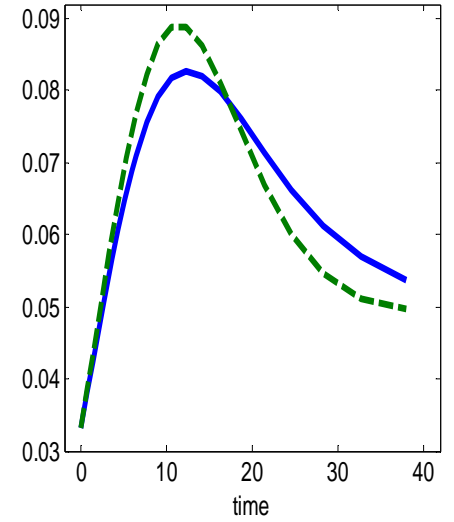

(vi) EFFORT

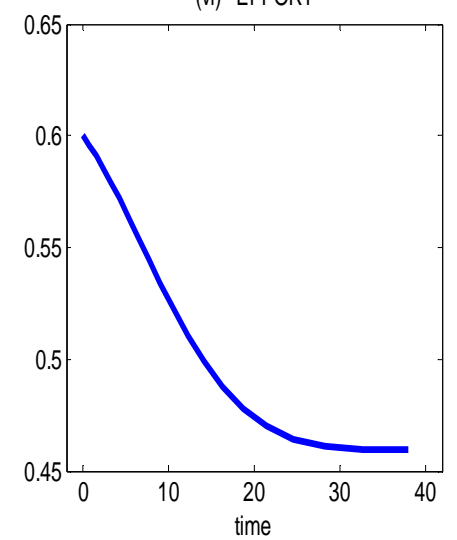

Note. Both lines display the transition of economies with wage inertia and the following initial conditions: $k_{0}=0.75 k^{*}$ and $\hat{w}_{0}=1.1 \hat{w}^{*}$. Continuous (dashed) lines show the transition of an economy with an internal (external) reference wage. 